\title{
Rural-Urban and Within-Rural Differences in COVID-19 Mortality Rates
}

\author{
Yue Sun, Syracuse University (ysun46@syr.edu) \\ Kent Jason Cheng, Syracuse University (kgcheng@syr.edu) \\ Shannon M. Monnat*, Syracuse University (smmonnat@syr.edu)
}

November 8, 2021

${ }^{*}$ Corresponding Author

Acknowledgements: The authors acknowledge support from two research networks funded by the National Institute on Aging (R24 AG065159 and 2R24 AG045061), the NIA-funded Center for Aging and Policy Studies at Syracuse University (P30AG066583), the NICHD-funded Population Research Institute at Penn State (P2CHD041025), the USDA Agricultural Experiment Station Multistate Research Project: W4001, Social, Economic and Environmental Causes and Consequences of Demographic Change in Rural America, and the Syracuse University Lerner Center for Public Health Promotion. 


\title{
Rural-Urban and Within-Rural Differences in COVID-19 Mortality Rates
}

\begin{abstract}
Since late-2020, COVID-19 mortality rates have been higher in rural than in urban America, but there has also been substantial within-rural heterogeneity. Using CDC data, we compare COVID-19 mortality rates across the rural-urban continuum as well as within rural counties across different types of labor markets and by metropolitan adjacency. As of October 1, 2021, the cumulative COVID-19 mortality rate was 247.0 per 100,000 population in rural counties compared to 200.7 in urban counties. Higher COVID-19 mortality rates in rural counties are explained by lower average educational attainment and lower median household income. Within rural counties, mortality rates have been highest in farmingdependent counties and lowest in recreation-dependent counties. Those differences are similarly explained by differences in educational attainment and median household income. Our findings have implications for ongoing COVID-19 prevention and vaccination efforts as well as for informing preparation efforts for future infectious disease outbreaks.

KEYWORDS

COVID-19, labor markets, mortality, rural U.S.
\end{abstract}




\section{INTRODUCTION}

As of October 2021, there have been over 42.6 million COVID-19 infections and over 693,760 deaths in the U.S. In the early phase of the COVID-19 outbreak (March-June 2020), infections and deaths were predominantly clustered in urban areas. By late-summer and early-fall, cases and deaths started to increase at a faster pace in rural areas, but urban cases and death rates remained higher. By December 2020, rural death rates had surpassed those in urban areas and have remained higher ever since.

Higher urban COVID-19 infection and mortality rates during the early part of the pandemic were largely attributable to higher population density and location of transportation hubs that facilitate quick spread (Karim and Chen 2020; Paul et al. 2020; Sun 2020; Zhang and Schwartz 2020). However, in the pandemic's later phases, cases quickly spread to rural communities, with large outbreaks clustered in counties with among the smallest populations (Leatherby 2020). Moreover, vaccination rates have been lower in rural than in urban areas, especially in farming and mining-dependent counties (Sun and Monnat 2021). The costs of COVID19 to individuals and families have been monumental. COVID-19 has also had detrimental consequences to local public health systems and economies. Therefore, it is critical to understand which types of places have been most affected and what factors are driving these differences.

Accordingly, this paper 1) describes rural-urban differences in COVID-19 mortality rates as well as variation within rural counties by categories of economic dependence and metropolitan adjacency, and 2) identifies the factors that explain these differences.

We found significantly higher mortality rates in rural counties than in urban counties overall. We also found substantial variation within rural counties, with the highest mortality rates in farming-dependent counties and the lowest rates in recreation-dependent counties. Both rural-urban and within-rural differences in COVID-19 mortality rates are explained by differences in educational attainment composition and median household income. Our findings have implications for ongoing COVID-19 prevention and vaccination efforts as well as for informing preparation efforts for future infectious disease outbreaks.

The Rural Mortality Penalty as a Backdrop for Rural-Urban Differences in COVID-19 Mortality

Rural America has long faced a mortality disadvantage (Cosby et al. 2008, 2019; Elo et al. 2019; James 2014; James and Cossman 2017; James et 
al. 2018; Singh and Siahpush 2014; Monnat 2020a; Vierboom et al. 2019). The gap has grown over the past couple of decades and is pervasive across multiple disease and injury categories (Monnat 2020a). The rural mortality penality is grounded in the literarure on ecological determinants of population health, which include individual-level risk factors and behaviors, community contexts (e.g., economic and employment conditions, health care infrastructure), and macro-level conditions (e.g., state policies, industrial restructuing, population loss) that increase risk of or protect against adverse health outcomes and premature mortality. Rural areas have historically faced higher mortality rates from infectious disease outbreaks (Paynter et al. 2011; Shanks 2019) and regularly experience higher annual rates of influenza mortality (U.S. Centers for Disease Control and Prevention 2021). Many of the same risk factors for worse health outcomes and higher rates of mortality in rural areas overall also apply to COVID-19.

Compositionally, rural populations are older and face a higher chronic disease burden than urban populations, drastically increasing their risk of high rates of COVID-19 mortality (Monnat 2020b; Johnson 2020; Peters 2020). Nearly $20 \%$ of rural residents are age 65 or older compared to $15 \%$ in urban areas, and $65 \%$ of the U.S.'s small nonmetro counties (identified as rural-urban contiunuum codes 8 and 9) are considered "older age" counties where more than $20 \%$ of the population is age 65 or older (Monnat 2020b). Because older adults are at greater risk of dying from COVID-19, rural communities with larger shares of older adults are at risk of higher mortality rates. Moreover, rural populations are socioeconomically vulnerable, with higher rates of poverty (Thiede et al. 2018) and underemployment (Jensen and Slack 2003; Slack et al. 2020), and lower levels of education (Carr and Kefalas 2009) and health insurance coverage (Gong et al. 2019). These factors may influence health care access, prevention behaviors, and COVID-19 vaccination rates. A recent study found that county-level education, poverty, and racial/ethnic composition are strongly associated with COVID-19 mortality rates (Albrecht 2021). Lower county-level educational attainment also partially explains lower COVID-19 vaccination rates in rural counties compared to urban counties (Sun and Monnat 2021).

Rural communities also face several contextual disadvantages that put their populations at risk, including less robust health care and public health infrastructures, labor market disadvantages, and weaker state-level COVID-19 spread mitigation policies. In terms of health care infrastructure, since January 2005, 181 rural hospitals have closed, with a 
record 19 closures in 2020 alone (Cecil G. Sheps Center 2021). Many of the rural hospitals that are available have less capacity to deal with surges in cases, have limited medical personnel, and less access to ventilators and personal protective equipment for healthcare providers. Especially relevant for COVID-19 is that only $1 \%$ of the U.S.'s intensive care unit beds are located in rural areas (Society of Critical Care Management 2020). COVID-19 testing and vaccination rates have also been lower in rural areas (Monnat 2020b; Souch and Cossman 2021; Sun and Monnat 2021), increasing risk of community spread.

Differences in labor markets and working conditions may also place rural residents at increased risk. For example, rural workers were more likely to continue working during the pandemic and were less likely to work remotely (Brooks et al. 2021; Callaghan et al. 2021), and schools were more likely to remain open or operated remotely for much shorter periods (Gross and Opalka 2020). Government-deemed essential industries like meatpacking, agriculture, and prisons are disproportionately located in rural areas, placing workers at increased risk of infections (Hooks and Sawyer 2020; Peters 2020; Taylor, Boulos, and Almost 2020).

In addition, differences in political ideology and partisanship may contribute to higher rural mortality rates. Rural counties had much higher vote shares for Trump in the 2020 Presidential election, and county Trump vote share has been found to be associated with both lower vaccination rates (Sun and Monnat 2021) and higher COVID-19 case rates (Albrecht 2021). Rural residents have also been less likely than their urban peers to adopt COVID-19 prevention behaviors, such as physical distancing, avoiding dining out, and wearing face masks (Bruine de Bruin et al. 2020; Callaghan et al. 2021; Probst et al. 2020; Haischer et al. 2020). Rural residents are also less likely than their urban peers to report being worried about getting sick and are more likely to say that the severity is exaggerated (Kirzinger et al. 2021).

Related, state-level COVID-19 mitigation policies may also have played a role. For example, governors in rural states (those with lower population density) were slower to enact statewide state-at-home orders (Lin et al.2021) and were less likely to enact physical distancing mandates (Adolph et al. 2021) than governors in more urban states.

Within-Rural Variation in COVID-19 Vulnerability

For all of the reasons described above, we would expect rural communities in general to face a COVID-19 mortality penalty. However, rural areas are not homogenous. Just as the overall mortality penalty 
varies across rural areas (James 2014; Monnat 2020a), so too should we expect that COVID-19 mortality rates would vary across different types of rural communities.

Evidence suggests that infection trends have varied by adjacency to metro areas (Cheng et al, 2020; Sun 2020; Zhang and Schwartz 2020) and across different types of rural labor markets (Cohen 2020; Cromartie et al. 2020; Hooks and Sawyer 2020; Waltenburg 2020; USDA Economic Research Service 2021).

In terms of adjacency to metro areas, metro adjacent rural counties are at increased risk of COVID-19 spillover effects due to employment and recreation commuting patterns from neighboring urban hubs. Related to labor markets, the USDA Economic Research Service (ERS) classifies counties into economic dependency types based on wages and employment from specific industries. Their six mutually exclusive categories include farming, mining, manufacturing, government, recreation, and nonspecialized. Research on all-cause and cause-specific mortality trends finds substantially higher rates for most types of mortality in mining-dependent counties and comparatively lower rates in farmingdependent counties (Monnat 2020a). Recent research also shows that vaccination rates have been highest in recreation dependent counties and lowest in farming and mining dependent counties (Sun and Monnat 2021).

Specifically related to COVID-19 mortality rates, on the one hand, we might expect lower rates in farming-dependent counties due to lower population density which would reduce spread. On the other hand, farming-dependent counties face many of the risks described above. Many farming-dependent counties in the middle of the U.S. scored high on a community susceptibility scale developed by Peters (2020) in the early months of the pandemic. Their populations are older, more health compromised, and have comparatively lower educational attainment and median household income. Moreover, farming is essential work that cannot be done remotely. The agriculture industry often relies on undocumented laborers who might not be able to afford to miss work or are afraid to miss work if they are sick. Farm workers also have high uninsured rates, and health care availability is limited in these communities (Becot et al. 2020). Finally, states with large shares of farming-dependent counties have governors that were slow to enact stayat-home and physical distancing mandates (and mandates were shortlived) (Li et al 2021).

Mining-dependent rural counties might also be expected to have increased COVID-19 mortality risk given their higher rates of poverty, 
lower education, and higher rates of chronic diseases and relatedmortality including cancer and heart and respiratory diseases (Esch and Hendryx 2011; Hendryx, Fedorko, and Halverson 2010; Liu et al. 2021; Monnat 2020a). Environmental byproducts of mining, such as dust and other hazardous waste, harm respiratory health exacerbating the effects of a respiratory disease like coronavirus. Rural counties dominated by mining and farming have also historically been more politically conservative (Scala et al. 2017; Kaufman 2016; Lewin 2019) than other rural areas, which might drive up COVID-19 mortality rates for the same reasons outlined above.

Manufacturing-dependent counties may also be at risk of higher COVID-19 mortality rates (Peters 2020). Counties with meat processing plants have experienced large COVID-19 outbreak clusters (Cromartie 2020; USDA ERS 2021; Waltenburg 2020). As of July 2020, 23 states had reported outbreaks at meat and poultry processing plants (Waltenburg 2020), including in rural communities in Arkansas, Georgia, Nebraska, North Carolina, and South Dakota (Paschal 2020; Smith-Nonini 2020; Steinberg et al. 2020). An outbreak in two facilities in Nebraska was tied to 3,438 cases among workers alone, who then spread the disease to family and community members. Hispanic workers have been disproportionately affected due to their large concentration as workers in these types of facilities (Champlin and Hake 2006; Peters 2020). Working conditions (crowded, moist, cold) in meat processing plants and other manufacturing facilities are ideal for coronavirus spread (Reuben 2020). Moreover, many meat processing plants were found to be negligent in enacting safety measures (e.g., mandatory face masks and social distancing) in the early months of the pandemic and do not provide employees with paid sick leave or health insurance (Paschal 2020; Smith-Nonini and Paschal 2020). Because meat processing plants were classified as essential infrastructure, very few closed or reduced worker capacity during the pandemic (Paschal 2020; Smith-Nonini and Paschal 2020).

Much attention has been paid to outbreaks in prisons and the communities in which they are located (Hershow et al. 2020; Hooks and Sawyer 2020; Lewis et al. 2021; Ollove 2020; Schumaker 2020). Many rural communities have embraced prisons as an economic development strategy, and as a result, the nation's prisons are disproportionately located in rural areas (Lichter and Ziliak 2017). The USDA ERS includes prisons in the government-dependent employment category. Because of the crowded and unsanitary living conditions, the high prevalence of chronic health conditions among incarcerated people, and lack of personal 
protective supplies, prisons and jails were susceptible to coronavirus outbreaks (Ollove 2020; Schumaker 2020). For example, as of October 27 2020, almost half of the incarcerated population in South Dakota had contracted COVID-19 (Schumaker 2020). Cohen (2020) showed similar COVID-19 outbreaks in the early months of the pandemic that were linked to state prisons in rural counties in Arkansas, Kentucky, Louisiana, Tennessee, and Virginia. COVID-19 outbreaks in prisons have spillover effects in the local community, as prison workers carry the disease home with them after their shifts (Ollove 2020).

Unlike counties dominated by high-risk industries such as agriculture, mining, manufacturing, and government employment described above, communities that rely on recreation and services may have been protected against COVID-19. Recreation and services, such as restaurants, bars, and entertainment venues, were considered nonessential businesses by most state governments. Therefore, when stay-athome and business closure mandates were enacted, these businesses closed, reducing employees' and customers' exposure and community spread. Irrespective of government mandates, residents generally reduced their visits to these places, particularly during periods when case rates were increasing (Goolsbee and Syverson 2021). A recent study showed that recreation dependent rural counties had the highest vaccination rates among all rural labor market types (Sun and Monnat 2021), implying that the residents of these types of counties were more likely to take precautionary measures to prevent coronavirus spread. As a result, we might expect COVID-19 mortality rates to be lower in rural communities dependent on recreation.

\section{DATA AND METHODS}

This study included 3,142 U.S. counties. The dependent variable was the cumulative COVID-19 mortality rate (deaths per 100,000 population) as of October 1, 2021. Mortality data are from USA Facts (USA Facts 2021). Because COVID-19 mortality rates were normally distributed, we used ordinary least squares (OLS) regression for analyses. We focused on death counts instead of confirmed COVID-19 cases because the latter is susceptible to geographic bias in underreporting due to geographic disparities in testing, especially in resource-constrained rural areas (Peters 2020; Souch and Cossman 2021). However, we replicated all analyses using confirmed cases as the outcome (see Appendix Table 3 and 5). An important caveat of the CDC case data is that they include only 
new instances of reported cases, not instances when someone has been infected more than once.

In the first set of analyses, we compared COVID-19 mortality rates between rural and urban counties. We defined metro status using the USDA ERS Rural-Urban Continuum Codes (RUCC) for 2013 (USDA ERS 2020). We classified counties with RUCCs 4-9 as rural. We first ran models that adjusted only for state fixed effects to adjust for the clustering of counties within states and to account for unobserved variation in time invariant state characteristics, such as pre-COVID-19 policies and political orientation. Next, we introduced several county-level factors that may explain rural-urban variation in COVID-19 mortality rates in stepwise models. Sociodemographic composition factors included county percent non-Hispanic Black, percent Hispanic, percent age 65+, percent age 25+ with a bachelor's degree or more, median household income, and percentage without health insurance from the U.S. Census Bureau American Community Survey 2015-19 (ACS 2021). Health care resources included whether the county is a health professional shortage area and physicians per 100,000 population from the Area Health Resource Files, 2019-2020 (HRSA 2020). To account for political ideology and Trump influence, we included the 2020 Trump vote share from Dave Leip's Atlas of US Elections (Leip 2021). We generated quartiles for variables that were not normally distributed (percent non-Hispanic Black, percent Hispanic, and physician rate). We z-score standardized continuous variables (mean $=0$; standard deviation $=1$ ). In the main text, we present coefficients from the unadjusted and fully adjusted models. In a series of stepwise models shown in the Appendix, we determine which factors contribute most to rural-urban differences in COVID-19 mortality rates. Means and standard deviations for all variables are presented in Appendix Table 1.

In our second set of analyses, we restricted our sample to rural counties $(\mathrm{N}=1,976)$ to examine how county labor market type (economic dependence) and adjacency to metropolitan areas are associated with COVID-19 mortality rates. We classified labor markets based on the USDA ERS County Typology Codes (USDA ERS 2019), which include six mutually exclusive and exhaustive categories: nonspecialized, farming, mining, manufacturing, government, and recreation/services (reference group). The ERS determines its categorization based on the share of employment and earnings coming from each industry. For example, farming dependent counties are those with farm earnings accounting for an annual average of 25 percent or more of total county earnings or farm 
employment accounting for 16 percent or more of total employment in 2010-12. Each type has its own threshold of earnings and employment. Details about each type are provided in the ERS County Typology documentation (USDA ERS 2019). Metro adjacent counties are those with RUCCs of 4,6 , or 8 . We apply the same regression modeling strategy applied above to identify differences in COVID-19 mortality rates by labor market dependence and metro adjacency and identify the factors contributing to those differences.

\section{RESULTS}

As of October 1, 2021, the cumulative COVID-19 mortality rate was 247.0 per 100,000 population in rural counties compared to 200.7 in urban counties. Figure 1 shows the cumulative COVID-19 death rates (deaths per 100,000 population) by RUCC (Panel A) and average COVID-19 death rates by RUCC (Panel B). In general, rural counties (RUCCs 4-9) have higher COVID-19 mortality rates than urban counties (RUCCs 1-3). RUCC 2 counties have the lowest mortality rate (194.6 deaths per 100,000 population), while RUCC 6 have the highest mortality rate (270.0 deaths per 100,000 population).

\section{Figure 1. Cumulative COVID-19 Mortality Rates (deaths per 100,000 population) by $\mathrm{RUCC}(\mathrm{N}=3,142)$}

(A) COVID-19 Mortality Rate by RUCC

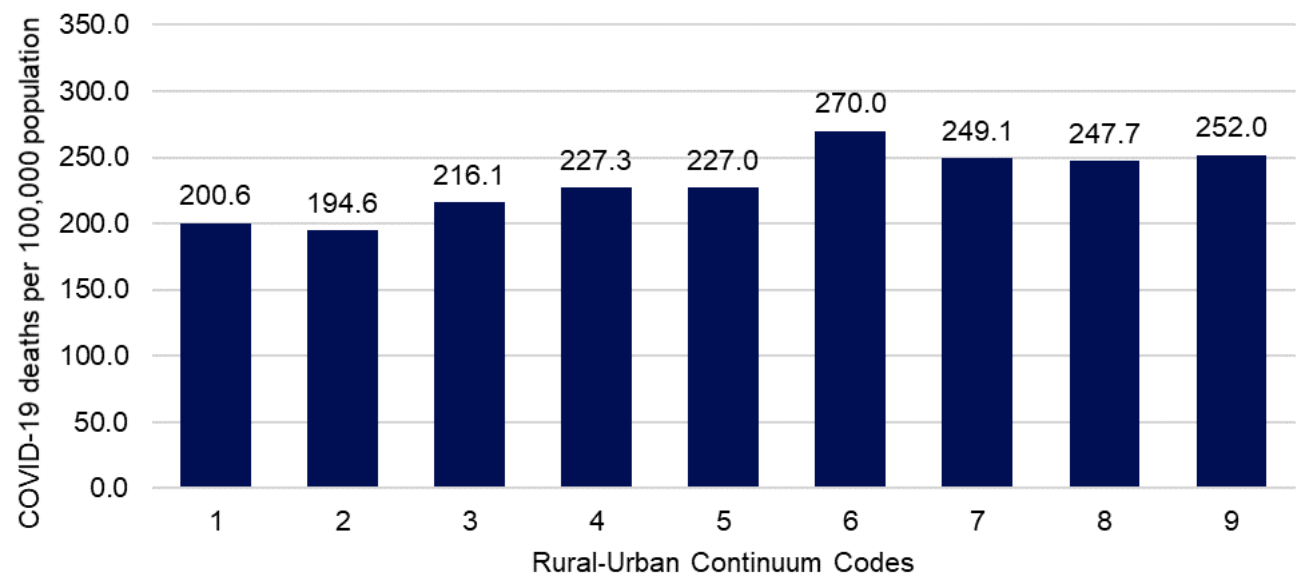


(B) Average COVID-19 Mortality Rate by RUCC

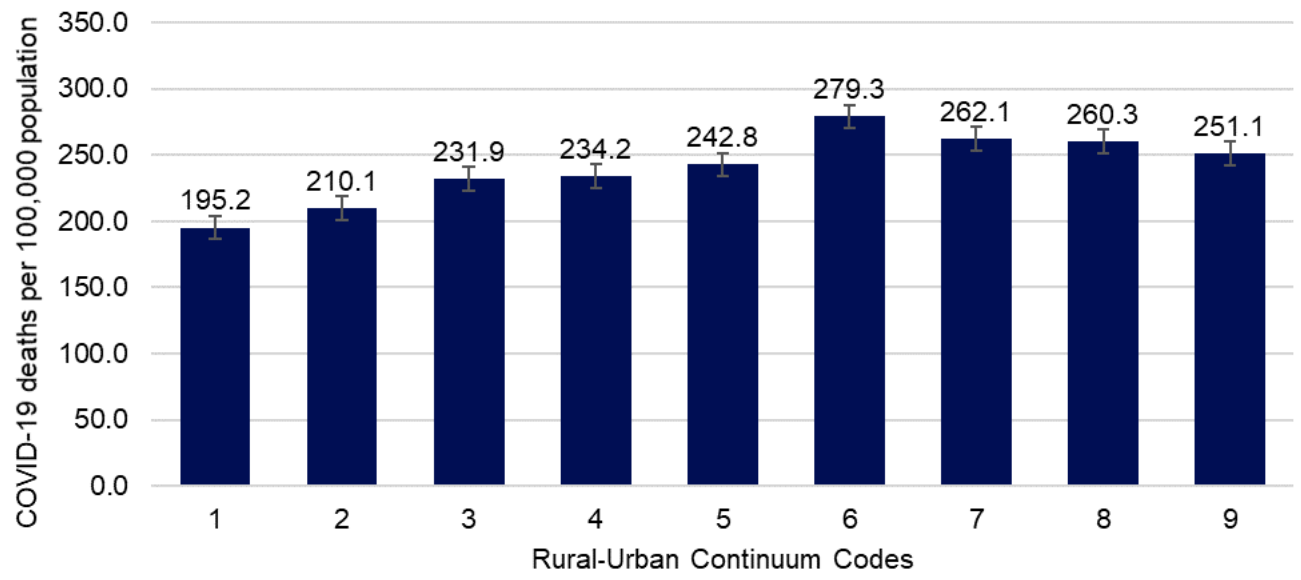

The first column of Table 1 presents regression coefficients from OLS models for each predictor, controlling only for state fixed effects. Controlling for state fixed effects. COVID-19 mortality rates generally increase with increasing rurality. RUCC 1 counties have the lowest mortality rates, while RUCC 6,7 , and 9 counties have the highest mortality rates. Collectively, RUCC and state fixed effects explain about $40 \%$ of the county-level variation in mortality rates, with state fixed effects contributing the most to between county variation. In terms of demographic and socioeconomic composition, mortality rates are significantly lower in counties with larger shares of Blacks and Hispanics, larger shares of adults with a Bachelor's degrees of higher, and counties with higher median household income. Rates are significantly higher in counties with larger shares of older adults and those with higher rates of uninsured residents. In terms of health care infrastructure, mortality rates are significantly higher in counties identified as health professional shortage areas and in those with fewer physicians per capita. Finally, higher Trump vote share is associated with significantly higher average COVID-19 mortality rates.

The model that includes all predictors is presented in the second column of Table 1. The only significant difference that remains is for RUCC 2; counties in RUCC 2 continue to have a significantly lower average COVID-19 mortality rate than counties in RUCC 1. Other factors that remain significant in the full model include percent of residents age $65+$, percent with a Bachelor's degree or more, median household income, percent without health insurance, and physicians per capita (which are associated with higher average mortality rates, perhaps because severe COVID-19 cases were transported to counties with larger hospitals and more physicians). 
Stepwise models, shown in Appendix Table 2 demonstrate that the primary contributors to rural-urban variation in COVID-19 mortality rates that we observed in the unadjusted model are education composition and median household income. The introduction of these variables dramatically reduced the RUCC coefficients and rendered all but RUCC 2 nonsignificant. Small metro (RUCC 3) and rural counties (RUCCs 4-9) have lower average educational attainment and lower average median household income than large urban (RUCC 1) counties. Both factors are associated with higher COVID-19 mortality rates. In fact, the introduction of educational composition and median household income reversed the sign for RUCCs 8 and 9. Although the coefficients are not significant, the reversal suggests that if small rural counties had the same education and income composition as large urban counties, small rural counties would actually have lower COVID-19 mortality rates, holding all else constant. The introduction of health care variables and Trump vote share did not lead to any additional meaningful changes in the RUCC coefficients, suggesting that they are not the primary contributors to rural-urban differences in COVID-19 mortality rates.

$<$ Table 1 here $>$

In supplemental analysis presented in Appendix Table 3, we examined rural-urban differences in COVID-19 infection rates. There are important differences from the mortality analysis. First, in models that adjusted only for state fixed effects, cumulative average case rates were significantly higher in RUCCs 3-7, but significantly lower in RUCC 9 compared to RUCC 1. In the model that included all predictors, only RUCCs 5-7 continued to have significantly higher case rates compared to RUCC 1. In the adjusted model, case rates are also significantly higher in counties with larger shares of Hispanics, more physicians per capita, and larger Trump vote shares. Case rates are significantly lower in counties with larger shares of residents ages 65 and older, larger shares with a BA or higher, higher median household income, and larger shares without health insurance. The higher infection rates we observed for RUCCs 4-7 in the unadjusted model were explained in large part by differences in socioeconomic composition (lower educational attainment and lower median household income) compared to large urban counties. Some additional attenuation was due to higher Trump vote share in rural compared to urban counties. Nonetheless, the variables we included in the model were unable to fully explain higher infection rates in RUCCs 5- 
7. We caution readers against over-interpreting these findings, as case rates are prone to substantially more bias than mortality rates due to differences across counties in testing and reporting.

Within-Rural Variation in COVID-19 Mortality Rates

The remainder of our analysis was restricted to rural counties. Figure 2 shows cumulative COVID-19 mortality rates (deaths per 100,000 population) by ERS economic dependence category for rural counties (Panel A) and average COVID-19 death rates by economic dependence for rural counties (Panel B). Recreation-dependent counties have the lowest aggregate mortality rate (168.6 deaths per 100,000 population), while nonspecialized counties have the highest aggregate mortality rates (268.3 deaths per 100,000 population). Recreation counties also have the lowest average mortality rate (175.2 per 100,000 population), while the average mortality rate is highest among farming-dependent counties (268.8 deaths per 100,000 population).

Figure 2. Cumulative COVID-19 Mortality Rates (deaths per 100,000 population) by Economic Dependency for Rural Counties ( $N=1,976)$

(A) COVID-19 Mortality Rate by Economic Dependency

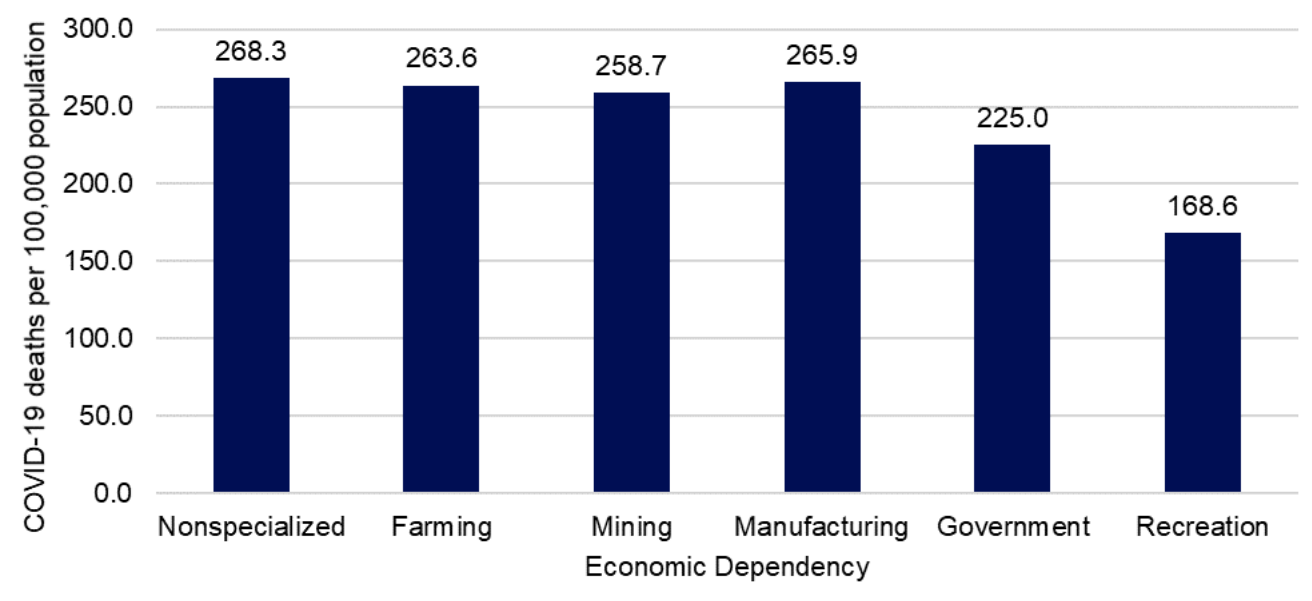


(B) Average COVID-19 Mortality Rate by Economic Dependency

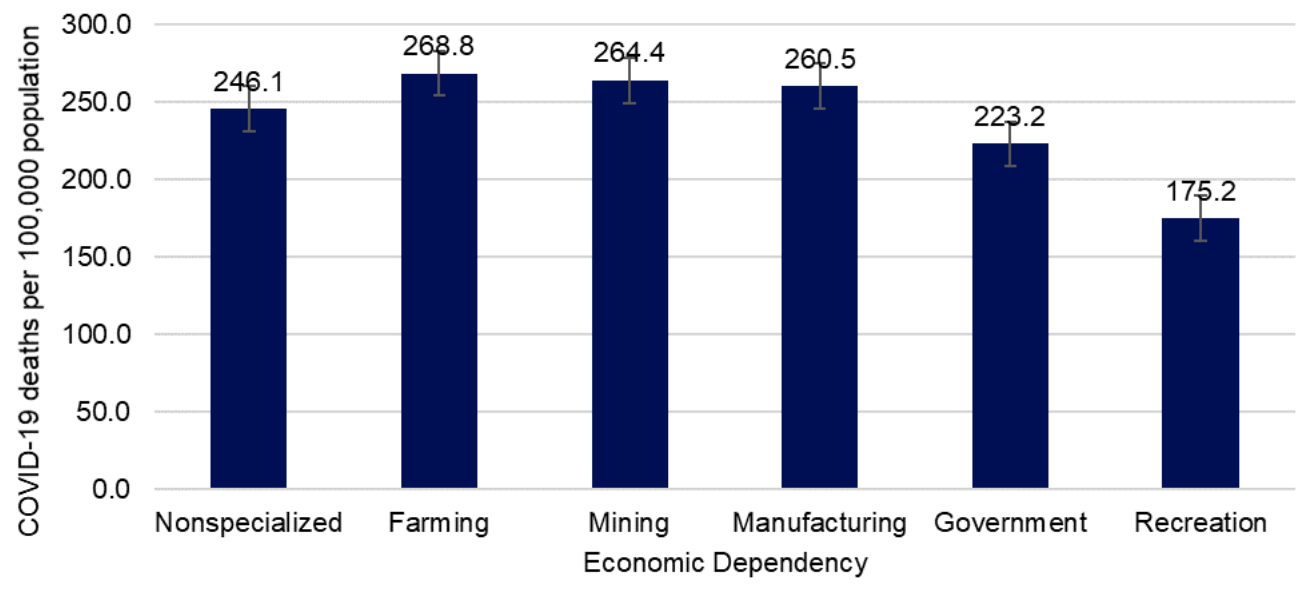

Note: Mortality rates are current as of October 1, 2021

Results from OLS regression models predicting COVID-19 mortality rates by economic dependence type for rural counties are presented in Table 2. The first column presents regression coefficients for each predictor, controlling only for state fixed effects. Non-specialized, farming dependent, and manufacturing dependent counties have higher average COVID-19 mortality rates than recreation dependent counties. Together, labor market type and state fixed effects explain about $42 \%$ of the countylevel variation in rural mortality rates, with nearly all of the between-county variation explained by state fixed effects rather than economic dependence. Adjacency to a metro area is not significantly associated with COVID-19 mortality rates.

In terms of demographic and socioeconomic composition, controlling only for state fixed effects, COVID-19 mortality rates are significantly higher in rural counties with larger shares of adults age 65+ and larger shares of residents without health insurance. Rates are significantly lower in counties with larger shares of adults with a Bachelor's degree or higher and in counties with higher median household income. Health care infrastructure factors and Trump vote share were not significantly associated with COVID-19 mortality rates in rural counties.

In the model that includes all predictors (second column of Table 2), non-specialized, farming, and manufacturing counties continue to have higher average COVID-19 mortality rates than recreation counties, but farming is the only type that remained statistically significant $(p<.05)$. Holding all else constant, rural farming counties have an average COVID19 mortality rate that is 24.3 deaths per 100,000 population higher than rural recreation counties. 
Stepwise regression models (show in Appendix Table 4) revealed that higher COVID-19 mortality rates in non-specialized, farming, and manufacturing counties that we observed in the unadjusted model were driven by lower educational attainment and lower median household income.

$<$ Table 2 here $>$

We conducted supplemental analysis on within-rural differences in infection rates, with results presented in Appendix Table 5. In the model that includes only state fixed effects, non-specialized, mining, manufacturing, and government dependent counties all had significantly higher case rates than recreation counties. The introduction of demographic predictors (racial/ethnic and age composition) explained the disadvantage for both mining and government dependent counties and drastically attenuated the disadvantage for manufacturing dependent and non-specialized counties. The additional inclusion of socioeconomic composition factors (particularly educational attainment) changed the direction of the sign for farming and mining dependent counties. This implies that holding all else constant, if farming and mining dependent counties shared the same educational attainment profile as recreation counties, mining and farming counties would actually have significantly (and substantively) lower COVID-19 case rates than recreation counties. Of course, educational attainment may be serving as a proxy for differences in types of jobs that can be done remotely versus jobs that can only be done in person. Unlike with the analysis of rural-urban differences in infection rates, Trump vote share did not contribute to within-rural variation in infection rates.

\section{DISCUSSION}

Rural America has long faced a mortality disadvantage (Cosby et al. 2008, 2019; Elo et al. 2019; James 2014; James and Cossman 2017; James et al. 2018; Singh and Siahpush 2014; Monnat 2020a; Vierboom et al. 2019), so it is no surprise that rural communities would also be disproportionately impacted by COVID-19 mortality (Monnat 2020b). The objective of this study was to describe rural-urban and within-rural variation in COVID-19 mortality rates. There are several important takeaways.

As of October 1, 2021, the cumulative COVID-19 mortality rate was about $23 \%$ higher in rural than in urban counties. In models that adjusted only for state fixed effects, mortality rates increased in a nearly monotonic 
relationship with rurality. However, our stepwise models showed that there does not appear to be anything about rural residence per se (e.g., health care factors) driving the rural COVID-19 mortality disadvantage. Instead, we found that the rural mortality disadvantage is explained by lower educational attainment and lower median household income in rural counties. These findings are consistent with those of another recent study (Albrecht 2021) and highlight the importance of aggregate level human capital and socioeconomic resources for preventing COVID-19 infection and deaths. This should come as no surprise as these same place-level factors are associated with geographic differences in mortality rates from many causes of death (Graetz and Elo 2021; James and Cossman 2017). In terms of protection against COVID-19, at the individual level, education and income shape preventive behaviors, such as mask use, social distancing, and vaccine uptake, as well as access to health care resources (Brough, Freedman, and Phillips 2021; Griffith, Evans, and Bor 2017; Khubchandani et al. 2021; Mondal, Sinharoy, and Su 2021; Papageorge et al. 2021). These findings are also in line with fundamental cause theory, which posits that SES embodies an array of resources, such as money, knowledge, and power than protect health in the face of multiple disease threats (Link and Phelan 1995; Phelan et al. 2010). Educational attainment also influences access to different types of employment. Rural residents are more likely to work in occupations that do not require a college degree, but also that cannot be done remotely. Rural workers were more likely to continue working during the pandemic and were less likely to work remotely (Brooks et al. 2021; Callaghan et al. 2021). This may have increased the risk of community spread. Given that our analyses are ecological we must be cautious about attributing individual behaviors to the relationships we observed, but it is possible that places with more highly educated and affluent residents enjoyed both structural advantages (such as greater ability to work from home) and greater community-level uptake of preventive behaviors.

We extend the prior research on rural-urban continuum differences in COVID-19 mortality (Albrecht 2021) by also examining mortality differences between rural counties by metro adjacency and across different types of labor markets. Contrary to our expectations, adjacency to a metro area was not associated with COVID-19 mortality (or infection) rates. However, there are important differences across different types of labor markets. We found that rural counties dependent on farming or manufacturing, as well as those categorized as non-specialized, have had higher COVID-19 mortality rates than recreation dependent rural counties. 
Service-related business closures and event cancellations early on likely protected residents of service and recreation-heavy areas against COVID19 spread. However, the picture is not completely rosy. Business closures and high rates of unemployment may have long-term economic consequences in these communities which could affect population health for years to come. In a recent study focused on the rural West (where many recreation-dependent counties are located), Mueller et al. (2021) found severe impacts of COVID-19 on unemployment, overall life satisfaction, mental health, and economic outlook. This portends future consequences to population health in these communities despite being comparatively protected from COVID-19 itself.

We found that much of the rural farming disadvantage and all of the rural manufacturing and non-specialized county disadvantage was explained by lower educational attainment and lower median household income in these types of rural counties, potentially for the same reasons posited above. But education and income may also be proxies for job characteristics and work settings. Farming and manufacturing jobs do not require higher education and also come with comparatively low wages. Farming and manufacturing cannot be done remotely, and workers in both of these industries were deemed essential throughout the pandemic. The agriculture industry often relies on undocumented laborers who might not be able to afford to miss work or are afraid to miss work if they are sick. Factories in rural areas were vectors for COVID-19 outbreaks early on in the pandemic due to their tight quarters and lax safety measures (Cromartie 2020; Paschal 2020; Reuben 2020; Smith-Nonini and Paschal 2020; Steinberg et al. 2020; Waltenburg 2020; USDA ERS 2021).

Finally, in supplemental analysis, we examined rural-urban and within-rural differences in COVID-19 infection rates. In the case of infections, rates are higher overall in counties with larger shares of Hispanics, more physicians per capita, and larger Trump vote shares, and are lower overall in counties with larger shares of older residents (suggesting that residents of these counties may have engaged in more preventive behaviors to protect older adult residents), higher educational attainment, higher median household income, and larger shares without health insurance (suggesting that insurance coverage may influence testing rates). Within rural counties, recreation counties had the lowest infection rates, with much of this advantage explained by differences in racial/ethnic and age composition and educational attainment. However, we caution readers against over-interpreting these findings, as case rates 
are prone to substantially more bias than mortality rates due to differences across counties in testing and reporting.

COVID-19 will have profound long-term implications for rural population health. The pandemic has exacerbated existing challenges with health care availability in rural areas. Many rural hospitals, already stretched thin before the pandemic, may not survive from the financial fallout, leading to increases in the already rapid rate of rural hospital closures (Goodhill 2021). There are also potential longer-term consequences for economic security. About $18 \%$ of small nonmetropolitan counties are economically dependent on recreation compared to only $10 \%$ of large metropolitan counties. Massive layoffs of employees working in restaurants and bars, hotels, entertainment, and other hospitality venues during the early stages of COVID-19, along with current labor shortages in these industries, could lead to increases in small business closures, economic instability, and worker stress, with disproportionate effects on rural communities that have limited capacity to pivot to other economic development strategies.

Several interventions are needed to reduce continued spread and to prepare for future pandemics. In the immediate term, efforts must be made to increase vaccination rates in rural communities. Recent research shows that rural counties (especially those reliant and mining or farming) have significantly lower vaccination rates than urban counties, explained mostly by differences in Trump vote share and educational attainment (Sun and Monnat 2021). This suggests the need to combat misinformation to reduce vaccine resistance in these types of places, especially now that children age 5 and up are eligible for the vaccine. Recent polls suggest that rural residents trust their primary care physicians to provide reliable information about the COVID-19 more than the FDA, CDC, or local public health departments (Kirzinger et al. 2021). This means physicians are ideal messengers for communicating the importance of getting vaccinated. The National Rural Health Association has provided several tools for rural community, health care, agricultural, and faith leaders to help reduce vaccine resistance, including talking points, op-ed templates, and public service announcements (NRHA 2021). Recent upticks in adult vaccination rates suggest that government and employer mandates may also be playing a critical role (Hsu 2021). Rural communities must also prepare for future pandemics. This includes stepping up the testing and contact tracing apparatus in places that we know are at high risk of communicable disease spread (including those with essential businesses and crowded working environments). Such efforts will require state and federal 
governments to invest resources to strengthen rural health care systems and public health infrastructure.

\section{Limitations}

Findings should be considered in light of some limitations. First, this study is ecological, and causality cannot be established. Second, data availability restricted us to examining variation at the county level, but counties may not be the most appropriate spatial scale for understanding geographic heterogeneity in mortality or infection rates. Just as there is variation between counties, there is also variation within counties, with certain population pockets at greater risk than others. Counties also vary dramatically by size. This is particularly relevant for rural counties. Eastern rural counties are comparatively small, whereas rural counties in the West are large and often separated by natural barriers, such as mountains and lakes. This gives rise to the well-known modifiable areal unit problem, where conclusions may be different depending on the spatial scale at which the outcome is aggregated. Third, because we restricted our subanalysis to rural counties, we did not account for spatial spillover across neighboring counties. Because COVID-19 is an infectious disease, there is certainly spatial autocorrelation in the distribution of COVID-19 deaths. Fourth, state-level variation in COVID-19 mitigation policies may have contributed to metropolitan status differences in mortality rates. There was widespread variation in the adoption and timing of stay-at-home orders, mask mandates, and non-essential business closures. Our inclusion of state fixed effects controls for non-time varying unobserved state level differences, but cannot account for policy variation during the pandemic. Much of the unexplained between-county variation in mortality and infection rates may be due to different state policy choices. Studies exploring the effects specific state COVID-19 mitigation policies and geographic differences in COVID-19 spread are warranted.

\section{CONCLUSION}

We found large rural-urban and within-rural variation in COVID-19 mortality and infection rates in the U.S. COVID-19 mortality rates have been higher in rural counties, overall, with the highest rates observed in farming-dependent counties and the lowest rates in recreation-dependent counties. Higher rural COVID-19 mortality rates threaten to exacerbate the existing long-running rural mortality penalty and may have long term economic implications for rural areas. Federal, state, and local governments should enact economic and health policies that support 
access to health care resources and vaccines to reduce COVID-19 mortality disparities. Governments, local public health professionals, and employers must also work to increase vaccine uptake among those who remain resistant and prepare for future pandemics by establishing better protections for essential workers and implementing more uniform spread mitigation policies and procedures.

\section{DISCLOSURE STATEMENT}

No potential conflict of interest was reported by the authors.

\section{REFERENCES}

Adolph, Christopher, Amano, Kenya, Bang-Jensen, Bree, Fullman, Nancy, Wilkerson, John. 2021. "Pandemic Politics: Timing State-Level Social Distancing Responses to COVID-19." Journal of Health Politics, Policy and Law 46(2):211-33.

Albrecht, Don E. 2021. "COVID-19 in Rural America: Impacts of Politics and Disadvantage." Rural Sociology 1-25. doi: 10.1111/ruso.12404.

Becot, Florence, Shoshanah Inwood, Casper Bendixsen, and Carrie Henning-Smith. 2020. "Health Care and Health Insurance Access for Farm Families in the United States during COVID-19: Essential Workers without Essential Resources?" Journal of Agromedicine 25(4):374-77.

Brough, Rebecca, Matthew Freedman, and David C. Phillips. 2021. "Understanding Socioeconomic Disparities in Travel Behavior during the COVID-19 Pandemic." Journal of Regional Science 61(4):753-74.

Brooks, Matthew M., J. Tom Mueller, and Brian C. Thiede. 2021. "RuralUrban Differences in the Labor-Force Impacts of COVID-19 in the United States." Socius 7:1-12. doi: 10.1177/23780231211022094.

Bruine de Bruin, Wändi, Htay-Wah Saw, and Dana P. Goldman. 2020. "Political Polarization in US Residents' COVID-19 Risk Perceptions, 
Policy Preferences, and Protective Behaviors." Journal of Risk Uncertainty 61(2):177-94.

Callaghan, Timothy, Jennifer A. Lueck, Kristin Lunz Trujillo, and Alva O.

Ferdinand. 2021. "Rural and Urban Differences in COVID-19

Prevention Behaviors." The Journal of Rural Health 37(2):287-95. doi: https://doi.org/10.1111/jrh.12556.

Carr, Patrick J., and Maria J. Kefalas. 2009. Hollowing Out the Middle:

The Rural Brain Drain and What It Means for America. Boston, MA:

Beacon Press.

Cecil G. Sheps Center. 2021. "Rural Hospital Closures." UNC Cecil G. Sheps Center for Health Services Research. Retrieved June 18, 2021 (https://www.shepscenter.unc.edu/programs-projects/ruralhealth/rural-hospital-closures/).

Champlin, Dell, and Eric Hake. 2006. "Immigration as Industrial Strategy in American Meatpacking." Review of Political Economy 18(1):49-70. doi: 10.1080/09538250500354140.

Cheng, Kent Jason G., Yue Sun, and Shannon M. Monnat. 2020. "COVID19 Death Rates Are Higher in Rural Counties With Larger Shares of Blacks and Hispanics." The Journal of Rural Health 36(4):602-8. doi: $10.1111 /$ jrh.12511.

Cohen, Philip N. 2020. "The COVID-19 Epidemic in Rural U.S. Counties." European Journal of Environment and Public Health 4(2):em0050. doi: 10.29333/ejeph/8331.

Cosby, Arthur G., Tonya T. Neaves, Ronald E. Cossman, Jeralynn S. Cossman, Wesley L. James, Neal Feierabend, David M. Mirvis, Carol A. Jones, and Tracey Farrigan. 2008. "Preliminary Evidence for an Emerging Nonmetropolitan Mortality Penalty in the United States." American Journal of Public Health 98(8):1470-72.

Cosby, Arthur G., M. Maya McDoom-Echebiri, Wesley James, Hasna Khandekar, Willie Brown, and Heather L. Hanna. 2019. "Growth and Persistence of Place-Based Mortality in the United States: The Rural Mortality Penalty." American Journal of Public Health 109(1):155-62. doi: 10.2105/AJPH.2018.304787.

Cromartie, John, Elizabeth A. Dobis, Thomas P. Krumel, David McGranahan, and John Pender. 2020. Rural America at a Glance, 2020 Edition. Retrieved June 21, 2021

(https://www.ers.usda.gov/publications/pubdetails/?pubid=100088).

Elo, Irma T., Arun S. Hendi, Jessica Y. Ho, Yana C. Vierboom, and Samuel H. Preston. 2019. "Trends in Non-Hispanic White Mortality in the United States by Metropolitan-Nonmetropolitan Status and Region, 1990-2016." Population and Development Review 45(3):549-83.

Esch, Laura, and Michael Hendryx. 2011. "Chronic Cardiovascular Disease Mortality in Mountaintop Mining Areas of Central 
Appalachian States." The Journal of Rural Health 27(4):350-57. doi: 10.1111/j.1748-0361.2011.00361.x.

Gong, Gordon, Scott G. Phillips, Catherine Hudson, Debra Curti, and Billy U. Philips. 2019. "Higher US Rural Mortality Rates Linked to Socioeconomic Status, Physician Shortages, and Lack of Health Insurance." Health Affairs 38(12):2003-10.

Goodhill, Olivia. 2021. "Shuttered Hospitals, Soaring COVID-19 Deaths: Rural Black Communities Lose a Lifeline in the Century's Worst Health Crisis." Retrieved June 21, 2021 (https://www.statnews.com/2021/05/26/shuttered-hospitals-soaringcovid19-deaths-rural-black-communities-lose-lifeline-in-pandemic/).

Goolsbee, Austan, and Chad Syverson. 2021. "Fear, Lockdown, and Diversion: Comparing Drivers of Pandemic Economic Decline 2020." Journal of Public Economics 193:104311. doi:

10.1016/j.jpubeco.2020.104311.

Graetz, Nick, and Irma T. Elo. 2021. "Decomposing County-Level Working-Age Mortality Trends in the United States Between 19992001 and 2015-2017." Spatial Demography. doi: 10.1007/s40980021-00095-6.

Griffith, Kevin, Leigh Evans, and Jacob Bor. 2017. "The Affordable Care Act Reduced Socioeconomic Disparities In Health Care Access." Health Affairs 36(8):1503-10.

Gross, Betheny and Opalka, Alice. 2020. "Too Many Schools Leave Learning to Chance during the Pandemic." Center on Reinventing Public Education. https://www.crpe.org/publications/too-manyschools-leave-learning-chance-during-pandemic.

Haischer, Michael H., Rachel Beilfuss, Meggie Rose Hart, Lauren Opielinski, David Wrucke, Gretchen Zirgaitis, Toni D. Uhrich, and Sandra K. Hunter. 2020. "Who Is Wearing a Mask? Gender-, Age-, and Location-Related Differences During the COVID-19 Pandemic." PLOS ONE 15(10):e0240785. doi: 10.1371/journal.pone.0240785.

Hendryx, Michael, Evan Fedorko, and Joel Halverson. 2010. "Pollution Sources and Mortality Rates Across Rural-Urban Areas in the United States." The Journal of Rural Health 26(4):383-91. doi: 10.1111/j.1748-0361.2010.00305.x.

Hershow, Rebecca B., Hannah E. Segaloff, Abigail C. Shockey, Kelsey R. Florek, Sabrina K. Murphy, Weston DuBose, Tammy L. Schaeffer, Jo Anna Powell, MPH, Krystal Gayle, Lauren Lambert, Amee Schwitters, Kristie E. N. Clarke, and Ryan Westergaard. 2021. "Rapid Spread of SARS-CoV-2 in a State Prison After Introduction by Newly Transferred Incarcerated Persons - Wisconsin, August 14-October 22, 2020." Morbidity and Mortality Weekly Report 70(13):478-82. doi: 10.15585/mmwr.mm7013a4.

Hooks, Gregory, and Wendy Sawyer. 2020. "Mass Incarceration, COVID19, and Community Spread." Prison Policy Initiative. Retrieved 
June 18, 2021

(https://www.prisonpolicy.org/reports/covidspread.html).

HRSA. 2020. "Area Health Resources Files." Health Resources \& Services Administration. Retrieved October 29, 2020 (https://data.hrsa.gov/data/download).

Hsu, Andrea. 2021. "Faced with Losing their Jobs, Even the Most Resistant are Getting Vaccinated." NPR. Retrieved November 8, 2021 (https://www.npr.org/2021/10/07/1043332198/employervaccine-mandates-success-workers-get-shots-to-keep-jobs). James, Wesley L. 2014. "All Rural Places Are Not Created Equal: Revisiting the Rural Mortality Penalty in the United States." American Journal of Public Health 104(11):2122-29. doi: 10.2105/AJPH.2014.301989.

James, Wesley, and Jeralynn S. Cossman. 2017. "Long-Term Trends in Black and White Mortality in the Rural United States: Evidence of a Race-Specific Rural Mortality Penalty." The Journal of Rural Health 33(1):21-31.

James, Wesley, Jeralynn Cossman, and Julia Wolf. 2018. "Persistence of Death in the United States: The Remarkably Different Mortality Patterns between America's Heartland and Dixieland." Demographic Research 39(33):897-910.

Jensen, Leif, and Tim Slack. 2003. "Underemployment in America: Measurement and Evidence." American Journal of Community Psychology 32(1-2):21-31.

Johnson, Kenneth. 2020. "An Older Population Increases Estimated COVID-19 Death Rates in Rural America." UNH Carsey School of Public Policy. Retrieved June 18, 2021 (https://carsey.unh.edu/publication/older-rural-pop-increasesestimated-COVID-death-rates).

Karim, Saleema A., and Hsueh-Fen Chen. 2020. "Deaths From COVID-19 in Rural, Micropolitan, and Metropolitan Areas: A County-Level Comparison." The Journal of Rural Health 0:1-9. doi: https://doi.org/10.1111/jrh.12533.

Kaufman, Chelsea N. 2008. "The Changing Political Character of American Farmers: 1954-2008." Journal of Rural Studies 47:153164. doi:10.1016/j.jrurstud.2016.07.030

Khubchandani, Jagdish, Sushil Sharma, James H. Price, Michael J. Wiblishauser, Manoj Sharma, and Fern J. Webb. 2021. "COVID-19 Vaccination Hesitancy in the United States: A Rapid National Assessment." Journal of Community Health 46:270-77.

Kirzinger, Ashley, Cailey Munana, and Mollyann Brodie. 2021. "Vaccine Hesitancy in Rural America." Kaiser Family Foundation. Retrieved June 21, 2021 (https://www.kff.org/coronavirus-covid-19/pollfinding/vaccine-hesitancy-in-rural-america/).

Leatherby, Lauren. 2020. "The Worst Virus Outbreaks in the U.S. Are Now in Rural Areas." The New York Times, October 22. 
Leip, Dave. 2021. "Dave Leip's Atlas of U.S. Presidential Elections." Retrieved August 19, 2021 (https://uselectionatlas.org/).

Lewin, Philip G. 2019. "Coal is Not Just a Job, It's a Way of Life": The Cultural Politics of Coal Production in Central Appalachia. Social Problems 66(1):51-68. doi:10.1093/socpro/spx030.

Lewis, Nathaniel M., Amelia Prebish Salmanson, Andrea Price, llene Risk, Colleen Guymon, Marcus Wisner, Kyle Gardner, Rena Fukunaga, Amee Schwitters, Lauren Lambert, Henry C. Baggett, Raimi Ewetola, and Angela C. Dunn. 2021. "Community-Associated Outbreak of COVID-19 in a Correctional Facility - Utah, September 2020-January 2021." Morbidity and Mortality Weekly Report 70(13):467-72. doi: 10.15585/mmwr.mm7013a2.

Lichter, Daniel T., and James P. Ziliak. 2017. "The Rural-Urban Interface: New Patterns of Spatial Interdependence and Inequality in America." The ANNALS of the American Academy of Political and Social Science 672(1): 6-25.

Li, Jie, Daniel Q. Huang, Biyao Zou, Hongli Yang, Wan Zi Hui, Fajuan Rui, Natasha Tang Sook Yee, Chuanli Liu, Sanjna Nilesh Nerurkar, Justin Chua Ying Kai, Margaret Li Peng Teng, Xiaohe Li, Hua Zeng, John A. Borghi, Linda Henry, Ramsey Cheung, and Mindie H. Nguyen. 2021. "Epidemiology of COVID-19: A Systematic Review and Meta-Analysis of Clinical Characteristics, Risk Factors, and Outcomes." Journal of Medical Virology 93(3):1449-58. doi: https://doi.org/10.1002/jmv.26424.

Lin, Ge, Tonglin Zhang, Ying Zhang, and Quanyi Wang. 2021. "Statewide Stay-at-Home Directives on the Spread of COVID-19 in Metropolitan and Nonmetropolitan Counties in the United States." Journal of Rural Health 37:222-223.

Link, Bruce G., and Jo Phelan. 1995. "Social Conditions As Fundamental Causes of Disease." Journal of Health and Social Behavior (Extra Issue):80-94.

Liu, Yang, Huan Lu, Wei Wang, Qi Liu, and Changju Zhu. 2021. "Clinical Risk Factors for Mortality in Patients with Cancer and COVID-19: A Systematic Review and Meta-Analysis of Recent Observational Studies." Expert Review of Anticancer Therapy 21(1):107-19. doi: 10.1080/14737140.2021.1837628.

Mondal, Pritish, Ankita Sinharoy, and Lilly Su. 2021. "Sociodemographic Predictors of COVID-19 Vaccine Acceptance: A Nationwide USBased Survey Study." Public Health 198:252-59.

Monnat, Shannon M. 2020a. "Trends in U.S. Working-Age Non-Hispanic White Mortality: Rural-Urban and Within-Rural Differences." Population Research and Policy Review. doi: https://doi.org/10.1007/s11113-020-09607-6.

Monnat, Shannon M. 2020b. "Why Coronavirus Could Hit Rural Areas Harder." Lerner Center for Public Health Promotion. Retrieved 
November 9, 2020 (https://lernercenter.syr.edu/2020/03/24/whycoronavirus-could-hit-rural-areas-harder/).

Mueller, J. Tom, Kathryn McConnell, Paul Berne Burow, Katie Pofahl, Alexis A. Merdjanoff, and Justin Farrell. 2021. "Impacts of the COVID-19 Pandemic on Rural America." Proceedings of the National Academy of Sciences 118(1):2019378118. doi: 10.1073/pnas.2019378118.

Ollove, Michael. 2020. "Analysis: How Covid-19 in Prisons and Jails Threatens the Surrounding Community." Daily Yonder. Retrieved October 22, 2020 (https://dailyyonder.com/analysis-how-covid-19in-prisons-and-jails-threatens-the-surroundingcommunity/2020/07/02/).

Papageorge, Nicholas W., Matthew V. Zahn, Michèle Belot, Eline van den Broek-Altenburg, Syngjoo Choi, Julian C. Jamison, and Egon Tripodi. 2021. "Socio-Demographic Factors Associated with SelfProtecting Behavior during the Covid-19 Pandemic." Journal of Population Economics 34:691-738.

Pappas, Stephanie. 2020. "COVID-19 Fallout Hits Farmers." American Psychological Association. Retrieved June 18, 2021 (https://www.apa.org/topics/covid-19/farming-communities-stress).

Paschal, Olivia. 2020. "Covid-19 Pounded Arkansas Poultry Workers as Government and Industry Looked On." Daily Yonder. Retrieved October 22, 2020 (https://dailyyonder.com/covid-19-poundedarkansas-poultry-workers-as-government-and-industry-lookedon/2020/08/28/).

Paul, Rajib, Ahmed Arif, Kamana Pokhrel, and Subhanwita Ghosh. 2021. "The Association of Social Determinants of Health With COVID-19 Mortality in Rural and Urban Counties." The Journal of Rural Health 37(2):278-86. doi: https://doi.org/10.1111/jrh.12557.

Paynter, S, R.S. Ware, and George D. Shanks. 2011. "Host and Environmental Factors Reducing Mortality during the 1918-1919 Influenza Pandemic. Epidemiology and Infection 139(9):14251430.

Peters, David J. 2020. "Community Susceptibility and Resiliency to COVID-19 Across the Rural-Urban Continuum in the United States." The Journal of Rural Health 36(3):446-56. doi: 10.1111/jrh.12477.

Phelan, Jo C., Bruce G. Link, and Parisa Tehranifar. 2010. "Social Conditions as Fundamental Causes of Health Inequalities: Theory, Evidence, and Policy Implications." Journal of Health and Social Behavior 51(1_suppl):S28-40.

Reuben, Anthony. 2020. "Coronavirus: Why Have There Been so Many Outbreaks in Meat Processing Plants?" BBC News. Retrieved December 4, 2020 (https://www.bbc.com/news/53137613).

Scala, Dante J. and Kenneth M. Johnson. 2017. "Political Polarization along the Rural-Urban Continuum? The Geography of the 
Presidential Vote, 2000-2016." Annals of the American Academy of Political and Social Science 672:162-84.

Schumaker, Erin. 2020. "Almost Half of South Dakota's Prison Population Tests Positive for COVID-19." ABC News. Retrieved October 30, 2020 (https://abcnews.go.com/Health/half-south-dakotas-prisonpopulation-tests-positive-covid/story?id=73853624).

Shanks, George D. 2019. "Epidemiological Isolation as an Infection Mortality Risk Factor in U.S. Soldiers from Late Nineteenth to Early Twentieth Centuries." America Journal of Tropical Medicine and Hygiene 101(5):980-983.

Singh, Gopal K., and Mohammad Siahpush. 2014. "Widening RuralUrban Disparities in Life Expectancy, U.S., 1969-2009." American Journal of Preventive Medicine 46(2): e19-29.

Slack, Tim, Brian C. Thiede, and Leif Jensen. 2020. "Race, Residence, and Underemployment: Fifty Years in Comparative Perspective, 1968-2017." Rural Sociology 85(2):275-315.

Smith-Nonini, Sandy. 2020. "Analysis: N.C.'s Rural Covid-19 Rate Stems from Meatpacking Plants." Daily Yonder. Retrieved October 22, 2020 (https://dailyyonder.com/analysis-n-c-s-rural-covid-19-ratestems-from-meatpacking-plants/2020/08/03/).

Smith-Nonini, Sandy, and Olivia Paschal. 2020. "As Covid-19 Hit Georgia Meatpacking Counties, Officials and Industry Shifted Blame." Daily Yonder. Retrieved October 22, 2020 (https://dailyyonder.com/ascovid-19-hit-georgia-meatpacking-counties-officials-and-industryshifted-blame/2020/09/15/).

Society of Critical Care Management. 2020. U.S. ICU Resource Availability for COVID-19. Accessed via: https://www.sccm.org/getattachment/Blog/March-2020/UnitedStates-Resource-Availability-forCOVID-19/United-States-ResourceAvailability-for-COVID-19.pdf?lang=en-US.

Souch, Jacob M. and Jeralynn S. Cossman. 2021. "A Commentary on Rural-Urban Disparities in COVID-19 Testing Rates per 100,000 and Risk Factors." Journal of Rural Health 37:188-190.

Steinberg, Jonathan, Erin D. Kennedy, Colin Basler, Michael P. Grant, Jesica R. Jacobs, Dustin Ortbahn, John Osburn, Sharon Saydah, Suzanne Tomasi, and Joshua L. Clayton. 2020. "COVID-19 Outbreak Among Employees at a Meat Processing Facility - South Dakota, March-April 2020." Morbidity and Mortality Weekly Report 69(31):1015-19. doi:

http://dx.doi.org.libezproxy2.syr.edu/10.15585/mmwr.mm6931a2.

Sun, Yue. 2020. "COVID-19 Cases Are Clustered in Large Urban Hubs, but Rural Areas Surrounding Those Hubs Are Also Increasingly Affected." Syracuse University Lerner Center for Public Health Promotion. Retrieved October 28, 2020 (https://lernercenter.syr.edu/2020/03/25/covid-19-cases-are- 
clustered-in-large-urban-hubs-but-rural-areas-surrounding-thosehubs-are-also-increasingly-affected/).

Sun, Yue, and Shannon M. Monnat. 2021. "Rural-Urban and within-Rural Differences in COVID-19 Vaccination Rates." The Journal of Rural Health 1-7. doi: 10.1111/jrh.12625.

Taylor, Charles A., Boulos, Christopher, Almond, Douglas. 2020. "Livestock Plants and COVID-19 Transmission." Proceedings of the National Academy of Sciences of the United States of America 117(50):31706-15.

Thiede, Brian C., Daniel T. Lichter, and Tim Slack. 2018. "Working, but Poor: The Good Life in Rural America?" Journal of Rural Studies 59:183-93. doi: 10.1016/j.jrurstud.2016.02.007.

US Census Bureau. 2021. "American Community Survey (ACS)." The United States Census Bureau. Retrieved May 5, 2021 (https://www.census.gov/programs-surveys/acs).

U.S. Centers for Disease Control and Prevention. 2020. People Who Are at Higher Risk for Severe Illness. https://www.cdc.gov/coronavirus/2019-ncov/need-extraprecautions/people-at-higher-risk.html.

U.S. Centers for Disease Control and Prevention, National Center for Health Statistics. Underlying Cause of Death 1999-2019 on CDC WONDER Online Database. Retrieved June 21, 2021 (http://wonder.cdc.gov/ucd-icd10.html).

USA Facts. 2021. "US COVID-19 Cases and Deaths by State." USA Facts. Retrieved May 5, 2021

(https://usafacts.org/visualizations/coronavirus-covid-19-spreadmap/).

USDA Economic Research Service. 2019. "County Typology Codes." United States Department of Agriculture Economic Research Service. Retrieved October 29, 2020 (https://www.ers.usda.gov/data-products/county-typology-codes/).

USDA Economic Research Service. 2020. "Rural-Urban Continuum Codes." United States Department of Agriculture Economic Research Service. Retrieved May 5, 2021 (https://www.ers.usda.gov/data-products/rural-urban-continuumcodes.aspx).

USDA Economic Research Service. 2021. "The COVID-19 Pandemic and Rural America. Retrieved June 21, 2021 (https://www.ers.usda.gov/covid-19/rural-america).

Vierboom, Yana C., Samuel H. Preston, and Arun S. Hendi. 2019. "Rising Geographic Inequality in Mortality in the United States." SSMPopulation Health 9:100478.

Waltenburg, Michelle A., Tristan Victoroff, Charles E. Rose, Marilee Butterfield, Rachel H. Jervis, Kristen M. Fedak, Julie A. Gabel, Amanda Feldpausch, Eileen M. Dunne, Connie Austin, Farah S. Ahmed, Sheri Tubach, Charles Rhea, Anna Krueger, David A. 
Crum, Johanna Vostok, Michael J. Moore, George Turabelidze, Derry Stover, Matthew Donahue, Karen Edge, Bernadette Gutierrez, Kelly E. Kline, Nichole Martz, James C. Rajotte, Ernest Julian, Abdoulaye Diedhiou, Rachel Radcliffe, Joshua L. Clayton, Dustin Ortbahn, Jason Cummins, Bree Barbeau, Julia Murphy, Brandy Darby, Nicholas R. Graff, Tia K. H. Dostal, Ian W. Pray, Courtney Tillman, Michelle M. Dittrich, Gail Burns-Grant, Sooji Lee, Alisa Spieckerman, Kashif Iqbal, Sean M. Griffing, Alicia Lawson, Hugh M. Mainzer, Andreea E. Bealle, Erika Edding, Kathryn E. Arnold, Tomas Rodriguez, Sarah Merkle, Kristen Pettrone, Karen Schlanger, Kristin LaBar, Kate Hendricks, Arielle Lasry, Vikram Krishnasamy, Henry T. Walke, Dale A. Rose, Margaret A. Honein, and COVID-19 Response Team. 2020. "Update: COVID-19 Among Workers in Meat and Poultry Processing Facilities - United States, April-May 2020." Morbidity and Mortality Weekly Report 69(27):887-92. doi:

http://dx.doi.org.libezproxy2.syr.edu/10.15585/mmwr.mm6927e2. Zhang, Charlie H., and Gary G. Schwartz. 2020. "Spatial Disparities in Coronavirus Incidence and Mortality in the United States: An Ecological Analysis as of May 2020." The Journal of Rural Health 36(3):433-45. doi: 10.1111/jrh.12476. 
Table 1: Ordinary Least Squares Regression Models Predicting COVID-19 Mortality Rates for U.S. Counties Overall

\begin{tabular}{|c|c|c|c|c|c|c|c|}
\hline & \multicolumn{4}{|c|}{ Unadjusted models } & \multicolumn{3}{|c|}{ Adjusted model } \\
\hline & Coefficient & SE & $p$ & $\mathrm{R}^{2}$ & Coefficient & SE & $p$ \\
\hline RUCC (Ref: 1) & & & & 0.398 & & & \\
\hline 2 & $17.27^{*}$ & 7.23 & 0.017 & & $-14.99^{*}$ & 7.23 & 0.038 \\
\hline 3 & $37.26^{\star \star \star}$ & 7.36 & $<0.001$ & & -5.42 & 7.60 & 0.476 \\
\hline 4 & $52.16^{\star \star \star}$ & 8.55 & $<0.001$ & & -2.29 & 8.95 & 0.798 \\
\hline 5 & $57.29^{\star \star \star}$ & 11.85 & $<0.001$ & & 2.72 & 11.84 & 0.819 \\
\hline 6 & $76.39^{* \star *}$ & 6.56 & $<0.001$ & & 5.99 & 7.50 & 0.424 \\
\hline 7 & $78.13^{\star \star *}$ & 7.27 & $<0.001$ & & 3.85 & 8.35 & 0.645 \\
\hline 8 & $63.19^{* * *}$ & 8.56 & $<0.001$ & & -11.92 & 9.62 & 0.216 \\
\hline $\begin{array}{l}9 \\
\text { \% Non-Hispanic Black } \\
\text { (Ref: Q1) }\end{array}$ & $76.28^{\star * *}$ & 7.61 & $<0.001$ & 0.359 & -2.76 & 9.19 & 0.764 \\
\hline Q2 & $-19.19^{\star \star *}$ & 5.48 & $<0.001$ & & -2.73 & 5.23 & 0.601 \\
\hline Q3 & $-25.25^{\star \star \star}$ & 5.92 & $<0.001$ & & 6.40 & 5.92 & 0.280 \\
\hline Q4 & $-16.74^{*}$ & 7.46 & 0.025 & & 12.89 & 7.84 & 0.100 \\
\hline \% Hispanic (Ref: Q1) & & & & 0.362 & & & \\
\hline Q2 & $-17.17^{\star \star}$ & 5.47 & 0.002 & & -0.20 & 5.19 & 0.969 \\
\hline Q3 & $-33.78^{* * *}$ & 5.81 & $<0.001$ & & -1.44 & 5.75 & 0.802 \\
\hline Q4 & $-30.58^{* * *}$ & 7.14 & $<0.001$ & & 5.77 & 7.24 & 0.426 \\
\hline $\begin{array}{l}\% \text { residents age } 65+ \\
\% \text { residents age } 25+\end{array}$ & $20.23^{* * *}$ & 1.92 & $<0.001$ & 0.377 & $11.02^{\star \star *}$ & 2.32 & $<0.001$ \\
\hline $\begin{array}{l}\text { with bachelor degree+ } \\
\text { Median household }\end{array}$ & $-41.23^{\star * *}$ & 1.93 & $<0.001$ & 0.438 & $-29.52^{\star \star \star}$ & 3.50 & $<0.001$ \\
\hline income & $-43.40^{\star * *}$ & 2.04 & $<0.001$ & 0.437 & $-18.33^{* * *}$ & 3.42 & $<0.001$ \\
\hline $\begin{array}{l}\% \text { No health insurance } \\
\text { Health professional }\end{array}$ & $24.02^{* * *}$ & 2.65 & $<0.001$ & 0.371 & $6.86^{*}$ & 2.85 & 0.016 \\
\hline $\begin{array}{l}\text { shortage area (Ref: no) } \\
\text { Physicians per } 100,000\end{array}$ & $28.76^{\star \star \star}$ & 6.32 & $<0.001$ & 0.359 & -2.67 & 6.03 & 0.658 \\
\hline population (Ref: Q1) & & & & 0.361 & & & \\
\hline Q2 & 3.34 & 5.25 & 0.525 & & $10.36^{*}$ & 4.95 & 0.036 \\
\hline Q3 & -4.16 & 5.30 & 0.432 & & $16.27^{\star *}$ & 5.24 & 0.002 \\
\hline Q4 & $-24.44^{\star * *}$ & 5.46 & $<0.001$ & & $24.17^{\star \star *}$ & 6.03 & $<0.001$ \\
\hline \% Trump vote, 2020 & $17.82^{\star \star \star}$ & 2.26 & $<0.001$ & 0.367 & -1.04 & 2.98 & 0.728 \\
\hline Constant & & & & & $306.96^{\star * *}$ & 15.84 & $<0.001$ \\
\hline $\mathrm{R}^{2}$ & & & & & 0.466 & & \\
\hline
\end{tabular}

Notes: $\mathrm{N}=3,141$ counties. ${ }^{* * *} \mathrm{p}<0.001,{ }^{* *} \mathrm{p}<0.01,{ }^{*} \mathrm{p}<0.05$. $\mathrm{Q}=$ quartile. Mortality rates are current as of October 1, 2021. All models control for state fixed effects. $R^{2}=0.354$ when the model includes only state fixed effects. 
Table 2: Ordinary Least Squares Regression Models Predicting COVID-19 Mortality Rates for Rural Counties

\begin{tabular}{|c|c|c|c|c|c|c|c|}
\hline & \multicolumn{4}{|c|}{ Unadjusted models } & \multicolumn{3}{|c|}{ Adjusted model } \\
\hline & Coefficient & SE & $p$ & $\mathrm{R}^{2}$ & Coefficient & SE & $p$ \\
\hline $\begin{array}{l}\text { Economic Dependence } \\
\text { (Ref: Recreation) }\end{array}$ & & & & 0.424 & & & \\
\hline Non-specialized & $36.06^{\star * *}$ & 9.11 & $<0.001$ & & 18.77 & 9.91 & 0.058 \\
\hline Farming & $42.23^{\star \star *}$ & 10.26 & $<0.001$ & & $24.35^{\star}$ & 10.96 & 0.026 \\
\hline Mining & 13.00 & 11.72 & 0.267 & & -1.04 & 12.69 & 0.935 \\
\hline $\begin{array}{l}\text { Manufacturing } \\
\text { Federal/ State }\end{array}$ & $22.01^{*}$ & 10.13 & 0.030 & & 10.35 & 11.00 & 0.347 \\
\hline $\begin{array}{l}\text { Government } \\
\text { Adjacent to metro (Ref: }\end{array}$ & 11.52 & 10.33 & 0.265 & & 0.97 & 11.16 & 0.930 \\
\hline $\begin{array}{l}\text { Not Adjacent to metro) } \\
\% \text { Non-Hispanic Black } \\
\text { (Ref: Q1) }\end{array}$ & -7.06 & 5.34 & 0.186 & $\begin{array}{l}0.416 \\
0.418\end{array}$ & -2.06 & 5.36 & 0.700 \\
\hline Q2 & $-19.42^{* *}$ & 6.61 & 0.003 & & -11.16 & 6.56 & 0.089 \\
\hline Q3 & -10.35 & 7.69 & 0.179 & & -4.67 & 7.84 & 0.552 \\
\hline Q4 & -4.31 & 11.14 & 0.698 & & -4.98 & 11.68 & 0.670 \\
\hline \% Hispanic (Ref: Q1) & & & & 0.415 & & & \\
\hline Q2 & -6.87 & 6.95 & 0.323 & & 1.43 & 6.82 & 0.834 \\
\hline Q3 & -6.29 & 7.82 & 0.421 & & 10.82 & 7.89 & 0.170 \\
\hline Q4 & -7.08 & 9.92 & 0.476 & & 6.74 & 10.31 & 0.513 \\
\hline $\begin{array}{l}\% \text { residents age } 65+ \\
\% \text { residents age } 25+\end{array}$ & $7.54^{* *}$ & 2.67 & 0.005 & 0.417 & 5.89 & 3.31 & 0.075 \\
\hline $\begin{array}{l}\text { with bachelor degree+ } \\
\text { Median household }\end{array}$ & $-37.24^{\star \star \star}$ & 3.80 & $<0.001$ & 0.443 & $-27.25^{\star \star \star}$ & 5.24 & $<0.001$ \\
\hline income & $-43.54^{\star * *}$ & 4.19 & $<0.001$ & 0.446 & $-27.12^{\star \star \star}$ & 5.40 & $<0.001$ \\
\hline $\begin{array}{l}\% \text { No health insurance } \\
\text { Health professional }\end{array}$ & $12.12^{\star \star \star}$ & 3.21 & $<0.001$ & 0.419 & 3.98 & 3.56 & 0.264 \\
\hline $\begin{array}{l}\text { shortage area (Ref: no) } \\
\text { Physicians per } 100,000\end{array}$ & 10.03 & 9.25 & 0.279 & 0.415 & -5.85 & 9.14 & 0.522 \\
\hline population (Ref: Q1) & & & & 0.416 & & & \\
\hline Q2 & 6.38 & 6.55 & 0.330 & & $13.96^{*}$ & 6.40 & 0.029 \\
\hline Q3 & 7.50 & 6.79 & 0.269 & & $23.02^{\star \star \star}$ & 6.84 & 0.001 \\
\hline Q4 & -2.63 & 7.64 & 0.731 & & $23.80^{\star \star}$ & 8.07 & 0.003 \\
\hline \% Trump vote, 2020 & 4.40 & 3.46 & 0.203 & 0.415 & -0.38 & 4.10 & 0.926 \\
\hline Constant & & & & & $298.39^{\star \star \star *}$ & 24.00 & $<0.001$ \\
\hline $\mathrm{R}^{2}$ & & & & & 0.465 & & \\
\hline
\end{tabular}

Notes: $\mathrm{N}=1,976$ rural counties. ${ }^{* \star *} \mathrm{p}<0.001,{ }^{* *} \mathrm{p}<0.01,{ }^{*} \mathrm{p}<0.05 . \mathrm{Q}=$ quartile.

Mortality rates are current as of October 1,2021 . All models control for state fixed effects. $R^{2}=0.415$ when model includes only state fixed effects. 


\section{APPENDIX}

Table 1: Means and Standard Deviations for Predictors by Rural-Urban Continuum Code (RUCC)

\begin{tabular}{|c|c|c|c|c|c|c|c|c|c|c|}
\hline & Full Sample & RUCC1 & RUCC2 & RUCC3 & RUCC4 & RUCC5 & RUCC6 & RUCC7 & RUCC8 & RUCC9 \\
\hline$\%$ Non-Hispanic & 8.9 & 12.2 & 10.8 & 9.4 & 8.3 & 7.9 & 10.1 & 7.0 & 10.3 & 3.7 \\
\hline Black & (14.4) & $(14.0)$ & (13.7) & (12.4) & (12.9) & (14.8) & (16.2) & (14.5) & (18.8) & (10.2) \\
\hline \multirow[t]{2}{*}{$\%$ Hispanic } & 9.4 & 11.0 & 10.5 & 8.6 & 10.0 & 13.2 & 9.3 & 10.5 & 5.3 & 7.6 \\
\hline & (13.9) & $(11.7)$ & (14.8) & (11.5) & (14.2) & (18.2) & $(15.1)$ & (16.2) & (8.8) & $(12.7)$ \\
\hline \multirow[t]{2}{*}{$\%$ age $65+$} & 18.8 & 15.6 & 17.3 & 17.7 & 18.1 & 16.5 & 19.3 & 19.4 & 22.0 & 22.2 \\
\hline & $(4.7)$ & (3.3) & $(4.0)$ & (4.7) & (3.6) & (3.8) & (3.4) & $(4.4)$ & $(4.7)$ & (5.3) \\
\hline$\%$ with Bachelor & 22.0 & 30.9 & 25.5 & 24.0 & 21.8 & 23.7 & 17.2 & 19.5 & 17.4 & 19.3 \\
\hline degree or higher & $(9.6)$ & (12.6) & $(9.2)$ & $(9.2)$ & $(7.8)$ & (8.7) & (6.1) & (7.3) & (5.9) & (6.9) \\
\hline Median household & 53475.9 & 71153.7 & 57218.0 & 54462.8 & 50968.8 & 52217.0 & 47933.5 & 48414.9 & 47135.4 & 49048.3 \\
\hline income $(\$)$ & (14192.5) & $(18454.0)$ & (11390.7) & $(9768.3)$ & (8976.8) & (12235.8) & (9678.7) & $(11111.6)$ & (10230.7) & $(11089.1)$ \\
\hline$\%$ No health & 9.6 & 8.1 & 8.8 & 8.8 & 9.0 & 10.1 & 10.5 & 10.4 & 10.3 & 10.7 \\
\hline insurance & $(5.1)$ & (3.9) & (4.3) & $(4.0)$ & (4.3) & (4.7) & (5.3) & $(5.7)$ & (4.9) & (6.5) \\
\hline $\begin{array}{l}\text { Health professional } \\
\text { shortage area }\end{array}$ & $89.5 \%$ & $80.1 \%$ & $90.2 \%$ & $89.0 \%$ & $87.9 \%$ & $89.1 \%$ & $91.2 \%$ & $89.6 \%$ & $98.2 \%$ & $92.5 \%$ \\
\hline Physicians per & 51.9 & 62.2 & 59.8 & 61.0 & 53.1 & 69.9 & 44.2 & 56.2 & 27.2 & 41.3 \\
\hline 100,000 & (37.2) & (37.9) & (33.5) & (48.6) & (22.0) & (28.5) & $(25.0)$ & (29.5) & (26.5) & (49.2) \\
\hline \multirow[t]{2}{*}{$\%$ Trump vote, 2020} & 64.8 & 53.3 & 58.7 & 62.1 & 62.1 & 61.4 & 68.4 & 68.8 & 69.7 & 74.6 \\
\hline & (16.2) & $(18.0)$ & (14.9) & $(14.4)$ & (12.3) & (15.2) & $(13.1)$ & (14.7) & (15.8) & (14.2) \\
\hline$N$ & 3142 & 432 & 378 & 356 & 214 & 92 & 593 & 433 & 220 & 424 \\
\hline
\end{tabular}


Table 2: Stepwise Ordinary Least Squares Regression Models Predicting COVID-19 Mortality Rates for U.S. Counties Overall

\begin{tabular}{|c|c|c|c|c|c|c|c|c|c|}
\hline & \multicolumn{3}{|c|}{ Unadjusted Model } & \multicolumn{3}{|c|}{ Demographic Predictors } & \multicolumn{3}{|c|}{ Socioeconomic Predictors } \\
\hline & $b$ & SE & $p$ & $b$ & SE & $p$ & $b$ & SE & $p$ \\
\hline \multicolumn{10}{|l|}{ RUCC (Ref: 1) } \\
\hline 2 & $17.27^{*}$ & 7.23 & 0.017 & $14.34^{*}$ & 7.24 & 0.048 & $-14.37^{*}$ & 7.21 & 0.046 \\
\hline 3 & $37.26^{\star * *}$ & 7.36 & $<0.001$ & $32.44^{* * *}$ & 7.39 & $<0.001$ & -5.22 & 7.52 & 0.488 \\
\hline 4 & $52.16^{\star * *}$ & 8.55 & $<0.001$ & $48.40^{\star \star *}$ & 8.58 & $<0.001$ & -1.63 & 8.84 & 0.854 \\
\hline 5 & $57.29^{* * *}$ & 11.85 & $<0.001$ & $54.60^{* * *}$ & 11.80 & $<0.001$ & 8.10 & 11.72 & 0.490 \\
\hline 6 & $76.39^{* * *}$ & 6.56 & $<0.001$ & $65.79^{* * *}$ & 6.83 & $<0.001$ & 7.10 & 7.41 & 0.338 \\
\hline 7 & $78.13^{\star * *}$ & 7.27 & $<0.001$ & $66.33^{\star * *}$ & 7.58 & $<0.001$ & 7.24 & 8.15 & 0.375 \\
\hline 8 & $63.19^{\star * *}$ & 8.56 & $<0.001$ & $43.21^{\star * *}$ & 9.19 & $<0.001$ & -15.88 & 9.47 & 0.094 \\
\hline 9 & $76.28^{* * *}$ & 7.61 & $<0.001$ & $53.82^{* * *}$ & 8.52 & $<0.001$ & -4.69 & 8.91 & 0.599 \\
\hline \multicolumn{10}{|l|}{ \% Non-Hispanic Black (Ref: Q1) } \\
\hline Q2 & & & & -8.37 & 5.46 & 0.126 & -3.80 & 5.22 & 0.467 \\
\hline Q3 & & & & -0.01 & 6.14 & 0.998 & 5.25 & 5.88 & 0.372 \\
\hline Q4 & & & & $16.40^{*}$ & 7.69 & 0.033 & 12.23 & 7.46 & 0.101 \\
\hline \multicolumn{10}{|l|}{ \% Hispanic (Ref: Q1) } \\
\hline Q2 & & & & -7.08 & 5.42 & 0.192 & 0.62 & 5.19 & 0.905 \\
\hline Q3 & & & & $-14.36^{*}$ & 5.94 & 0.016 & 0.29 & 5.73 & 0.960 \\
\hline Q4 & & & & -2.81 & 7.44 & 0.706 & 10.16 & 7.14 & 0.155 \\
\hline$\%$ residents age $65+$ & & & & $13.25^{\star \star \star}$ & 2.28 & $<0.001$ & $9.97^{\star \star *}$ & 2.21 & $<0.001$ \\
\hline$\%$ residents age $25+$ with bachelor degree+ & & & & & & & $-24.34^{\star * *}$ & 2.66 & $<0.001$ \\
\hline Median household income & & & & & & & $-21.99^{* * *}$ & 3.09 & $<0.001$ \\
\hline \multicolumn{10}{|l|}{$\%$ No health insurance } \\
\hline Health professional shortage area (Ref: no) & & & & & & & & & \\
\hline Physicians per 100,000 population (Ref: Q1) & & & & & & & & & \\
\hline
\end{tabular}




\begin{tabular}{llllllllll}
\hline Q2 & \\
Q3 & & & & & & & \\
Q4 & & & & & & & & \\
\% Trump vote, 2020 & $298.05^{* * *}$ & 13.13 & $<0.001$ & $302.00^{* * *}$ & 15.20 & $<0.001$ & $315.48^{* * *}$ & 14.57 & $<0.001$ \\
\hline Constant & 0.398 & & & 0.408 & & & 0.462 & & \\
$\mathrm{R}^{2}$ & & & & & & & & & \\
\hline
\end{tabular}

Table 2 cont: Stepwise Ordinary Least Squares Regression Models Predicting COVID-19 Mortality Rates for U.S. Counties Overall

\begin{tabular}{lllllll}
\hline & \multicolumn{3}{c}{ Health Care Predictors } & \multicolumn{3}{c}{ Trump Vote Share } \\
\cline { 2 - 7 } & \multicolumn{1}{c}{$\mathrm{b}$} & $\mathrm{SE}$ & $p$ & $\mathrm{~b}$ & $\mathrm{SE}$ & $p$ \\
\hline RUCC (Ref: 1) & & & & & & \\
2 & $-15.24^{*}$ & 7.20 & 0.034 & $-14.99^{*}$ & 7.23 & 0.038 \\
3 & -5.84 & 7.51 & 0.437 & -5.42 & 7.60 & 0.476 \\
4 & -2.67 & 8.88 & 0.764 & -2.29 & 8.95 & 0.798 \\
5 & 2.24 & 11.76 & 0.849 & 2.72 & 11.84 & 0.819 \\
6 & 5.58 & 7.40 & 0.451 & 5.99 & 7.50 & 0.424 \\
7 & 3.26 & 8.17 & 0.690 & 3.85 & 8.35 & 0.645 \\
8 & -12.36 & 9.53 & 0.195 & -11.92 & 9.62 & 0.216 \\
9 & -3.50 & 8.94 & 0.696 & -2.76 & 9.19 & 0.764 \\
\% Non-Hispanic Black (Ref: Q1) & & & & & & \\
Q2 & -2.76 & 5.22 & 0.597 & -2.73 & 5.23 & 0.601 \\
Q3 & 6.51 & 5.91 & 0.271 & 6.40 & 5.92 & 0.280 \\
Q4 & 13.64 & 7.53 & 0.070 & 12.89 & 7.84 & 0.100 \\
\% Hispanic (Ref: Q1) & & & & & & \\
Q2 & -0.25 & 5.18 & 0.962 & -0.20 & 5.19 & 0.969 \\
Q3 & -1.51 & 5.75 & 0.793 & -1.44 & 5.75 & 0.802 \\
\hline
\end{tabular}




\begin{tabular}{|c|c|c|c|c|c|c|}
\hline Q4 & 5.90 & 7.22 & 0.414 & 5.77 & 7.24 & 0.426 \\
\hline$\%$ residents age $65+$ & $10.89^{\star \star *}$ & 2.28 & $<0.001$ & $11.02^{\star \star \star}$ & 2.32 & $<0.001$ \\
\hline$\%$ residents age $25+$ with bachelor degree+ & $-28.91^{* * *}$ & 3.03 & $<0.001$ & $-29.52^{* * *}$ & 3.50 & $<0.001$ \\
\hline Median household income & $-18.73^{* \star *}$ & 3.22 & $<0.001$ & $-18.33^{* * *}$ & 3.42 & $<0.001$ \\
\hline$\%$ No health insurance & $7.05^{\star}$ & 2.80 & 0.012 & $6.86^{*}$ & 2.85 & 0.016 \\
\hline Health professional shortage area (Ref: no) & -2.68 & 6.03 & 0.657 & -2.67 & 6.03 & 0.658 \\
\hline \multicolumn{7}{|l|}{ Physicians per 100,000 population (Ref: Q1) } \\
\hline Q2 & $10.38^{*}$ & 4.94 & 0.036 & $10.36^{*}$ & 4.95 & 0.036 \\
\hline Q3 & $16.29^{* \star}$ & 5.24 & 0.002 & $16.27^{\star *}$ & 5.24 & 0.002 \\
\hline Q4 & $24.24^{\star \star *}$ & 6.03 & $<0.001$ & $24.17^{\star \star \star}$ & 6.03 & $<0.001$ \\
\hline$\%$ Trump vote, 2020 & & & & -1.04 & 2.98 & 0.728 \\
\hline Constant & $306.70^{\star \star *}$ & 15.82 & $<0.001$ & $306.96^{\star * *}$ & 15.84 & $<0.001$ \\
\hline $\mathrm{R}^{2}$ & 0.466 & & & 0.466 & & \\
\hline
\end{tabular}

Notes: $\mathrm{N}=3,141$ counties. ${ }^{* \star *} \mathrm{p}<0.001,{ }^{* \star} \mathrm{p}<0.01,{ }^{*} \mathrm{p}<0.05$. Q, quartile.

Mortality rates are current as of October $1,2021$.

All models control for state fixed effects. $R^{2}=0.354$ when model includes only state fixed effects. 
Table 3: Stepwise Ordinary Least Squares Regression Models Predicting COVID-19 Infection Rates for U.S. Counties Overall

\begin{tabular}{|c|c|c|c|c|c|c|c|c|c|}
\hline & \multicolumn{3}{|c|}{ Unadjusted Model } & \multicolumn{3}{|c|}{ Demographic Predictors } & \multicolumn{3}{|c|}{ Socioeconomic Predictors } \\
\hline & $b$ & SE & $p$ & $b$ & SE & $p$ & $b$ & SE & $p$ \\
\hline \multicolumn{10}{|l|}{ RUCC (Ref: 1) } \\
\hline 2 & 351.14 & 216.76 & 0.105 & $719.41^{* * *}$ & 210.04 & 0.001 & 251.95 & 213.62 & 0.238 \\
\hline 3 & $587.74^{\star *}$ & 220.67 & 0.008 & $1,076.43^{\star \star \star}$ & 214.45 & $<0.001$ & $446.09^{*}$ & 222.89 & 0.045 \\
\hline 4 & $971.13^{\star \star \star}$ & 256.30 & $<0.001$ & $1,438.36^{\star \star \star}$ & 249.00 & $<0.001$ & $574.58^{*}$ & 262.07 & 0.028 \\
\hline 5 & $1,593.60^{* * *}$ & 355.20 & $<0.001$ & $1,856.96^{* * *}$ & 342.24 & $<0.001$ & $1,087.53^{* *}$ & 347.33 & 0.002 \\
\hline 6 & $852.27^{\star \star \star}$ & 196.73 & $<0.001$ & $1,721.70^{\star \star \star}$ & 198.09 & $<0.001$ & $610.86^{\star *}$ & 219.63 & 0.005 \\
\hline 7 & $1,033.51^{* * *}$ & 217.88 & $<0.001$ & $1,979.11^{* * *}$ & 219.80 & $<0.001$ & $919.53^{* * *}$ & 241.59 & $<0.001$ \\
\hline 8 & -486.59 & 256.76 & 0.058 & $1,033.33^{* * *}$ & 266.73 & $<0.001$ & -76.95 & 280.75 & 0.784 \\
\hline 9 & $-712.71^{* *}$ & 228.21 & 0.002 & $943.05^{\star * *}$ & 247.20 & $<0.001$ & -124.77 & 264.14 & 0.637 \\
\hline \multicolumn{10}{|l|}{ \% Non-Hispanic Black (Ref: Q1) } \\
\hline Q2 & & & & 196.15 & 158.50 & 0.216 & $304.65^{*}$ & 154.64 & 0.049 \\
\hline Q3 & & & & $360.37^{*}$ & 178.07 & 0.043 & $520.58^{* *}$ & 174.25 & 0.003 \\
\hline Q4 & & & & -83.84 & 223.15 & 0.707 & -27.28 & 221.13 & 0.902 \\
\hline \multicolumn{10}{|l|}{ \% Hispanic (Ref: Q1) } \\
\hline Q2 & & & & 81.87 & 157.36 & 0.603 & 241.38 & 153.85 & 0.117 \\
\hline Q3 & & & & -141.88 & 172.49 & 0.411 & 169.17 & 169.86 & 0.319 \\
\hline Q4 & & & & $566.21^{* *}$ & 215.93 & 0.009 & $810.62^{* * *}$ & 211.64 & $<0.001$ \\
\hline $\begin{array}{l}\% \text { residents age } 65+ \\
\% \text { residents age } 25+\text { with bachelor }\end{array}$ & & & & $-926.96^{\star * *}$ & 66.28 & $<0.001$ & $-965.61^{* * *}$ & 65.36 & $<0.001$ \\
\hline degree+ & & & & & & & $-754.15^{* * *}$ & 78.83 & $<0.001$ \\
\hline Median household income & & & & & & & -159.50 & 91.52 & 0.081 \\
\hline $\begin{array}{l}\% \text { No health insurance } \\
\text { Health professional shortage area } \\
\text { (Ref: no) }\end{array}$ & & & & & & & & & \\
\hline
\end{tabular}




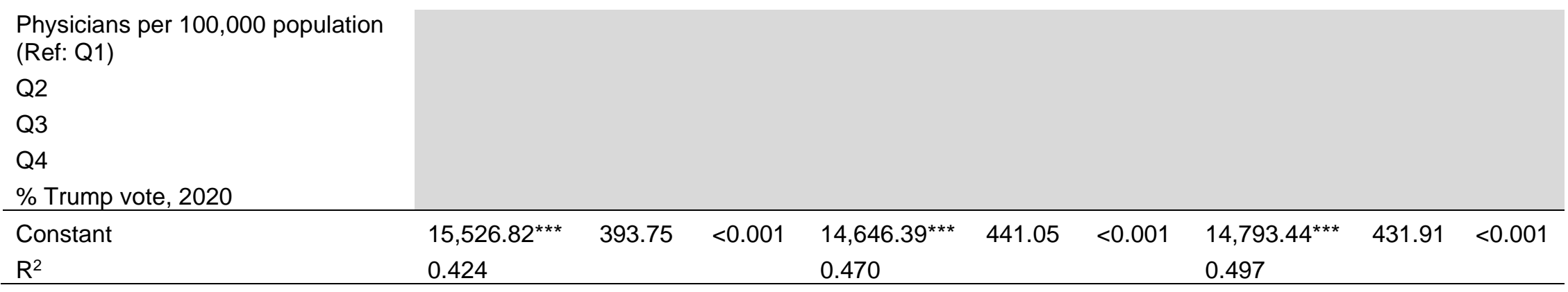

Table 3 cont: Stepwise Ordinary Least Squares Regression Models Predicting COVID-19 Infection Rates for U.S. Counties Overall

\begin{tabular}{|c|c|c|c|c|c|c|}
\hline & \multicolumn{3}{|c|}{ Health Care Predictors } & \multicolumn{3}{|c|}{ Trump Vote Share } \\
\hline & $b$ & SE & $p$ & $\mathrm{~b}$ & SE & $p$ \\
\hline \multicolumn{7}{|c|}{ RUCC (Ref: 1) } \\
\hline 2 & 174.22 & 212.50 & 0.412 & 79.56 & 212.80 & 0.709 \\
\hline 3 & 387.29 & 221.59 & 0.081 & 225.94 & 223.63 & 0.312 \\
\hline 4 & 486.40 & 262.12 & 0.064 & 338.62 & 263.23 & 0.198 \\
\hline 5 & $914.02^{\star *}$ & 347.14 & 0.009 & $729.18^{*}$ & 348.33 & 0.036 \\
\hline 6 & $597.04^{* *}$ & 218.47 & 0.006 & $435.10^{*}$ & 220.59 & 0.049 \\
\hline 7 & $853.63^{\star \star \star}$ & 241.16 & $<0.001$ & $624.16^{*}$ & 245.49 & 0.011 \\
\hline 8 & 145.48 & 281.42 & 0.605 & -25.88 & 282.96 & 0.927 \\
\hline 9 & 62.49 & 263.91 & 0.813 & -223.12 & 270.27 & 0.409 \\
\hline \multicolumn{7}{|c|}{ \% Non-Hispanic Black (Ref: Q1) } \\
\hline Q2 & 253.78 & 154.19 & 0.100 & 242.32 & 153.71 & 0.115 \\
\hline Q3 & $402.02^{*}$ & 174.43 & 0.021 & $444.90^{*}$ & 174.11 & 0.011 \\
\hline Q4 & -216.83 & 222.39 & 0.330 & 74.86 & 230.56 & 0.745 \\
\hline
\end{tabular}




\begin{tabular}{|c|c|c|c|c|c|c|}
\hline Q2 & 255.28 & 153.01 & 0.095 & 237.27 & 152.56 & 0.120 \\
\hline Q3 & 236.57 & 169.60 & 0.163 & 209.26 & 169.15 & 0.216 \\
\hline Q4 & $923.03^{* * *}$ & 213.25 & $<0.001$ & $974.32^{* \star *}$ & 212.85 & $<0.001$ \\
\hline$\%$ residents age $65+$ & $-1,063.19^{* * *}$ & 67.40 & $<0.001$ & $-1,115.94^{\star * *}$ & 68.15 & $<0.001$ \\
\hline$\%$ residents age $25+$ with bachelor degree+ & $-969.39^{* * *}$ & 89.43 & $<0.001$ & $-732.10^{* * *}$ & 103.00 & $<0.001$ \\
\hline Median household income & -183.46 & 95.02 & 0.054 & $-338.72^{\star * *}$ & 100.55 & 0.001 \\
\hline$\%$ No health insurance & $-374.02^{* * *}$ & 82.73 & $<0.001$ & $-300.83^{* * *}$ & 83.98 & $<0.001$ \\
\hline Health professional shortage area (Ref: no) & 218.84 & 177.96 & 0.219 & 217.15 & 177.38 & 0.221 \\
\hline \multicolumn{7}{|l|}{ Physicians per 100,000 population (Ref: Q1) } \\
\hline Q2 & $442.78^{\star \star}$ & 145.95 & 0.002 & $450.75^{\star \star}$ & 145.49 & 0.002 \\
\hline Q3 & $616.98^{\star \star *}$ & 154.66 & $<0.001$ & $625.60^{\star * \star}$ & 154.16 & $<0.001$ \\
\hline Q4 & $869.66^{\star \star \star}$ & 177.98 & $<0.001$ & $893.63^{* * *}$ & 177.48 & $<0.001$ \\
\hline$\%$ Trump vote, 2020 & & & & $403.80^{* * *}$ & 87.80 & $<0.001$ \\
\hline Constant & $14,201.55^{\star * *}$ & 466.99 & $<0.001$ & $14,097.93^{* * *}$ & 466.01 & $<0.001$ \\
\hline $\mathrm{R}^{2}$ & 0.505 & & & 0.508 & & \\
\hline
\end{tabular}

Notes: $\mathrm{N}=3,141$ counties. ${ }^{* *}{ }^{*} \mathrm{p}<0.001,{ }^{* *} \mathrm{p}<0.01,{ }^{*} \mathrm{p}<0.05 . \mathrm{Q}=$ quartile. Infection rates are current as of October $1,2021$. All models control for state fixed effects. 
Table 4: Stepwise Ordinary Least Squares Regression Models Predicting COVID-19 Mortality Rates for Rural Counties

\begin{tabular}{|c|c|c|c|c|c|c|c|c|c|}
\hline & \multicolumn{3}{|c|}{ Economic Dependence } & \multicolumn{3}{|c|}{ Metro Adjacency } & \multicolumn{3}{|c|}{ Demographic Predictors } \\
\hline & $\mathrm{b}$ & SE & $p$ & $\mathrm{~b}$ & SE & $p$ & $b$ & SE & $p$ \\
\hline \multicolumn{10}{|l|}{ Economic Dependency (Ref: Recreation) } \\
\hline Non-specialized & $36.06^{* * *}$ & 9.11 & $<0.001$ & $36.76^{\star * *}$ & 9.12 & $<0.001$ & $45.13^{\star * *}$ & 9.56 & $<0.001$ \\
\hline Farming & $42.23^{* * *}$ & 10.26 & $<0.001$ & $41.88^{* * *}$ & 10.26 & $<0.001$ & $44.96^{\star * *}$ & 10.43 & $<0.001$ \\
\hline Mining & 13.00 & 11.72 & 0.267 & 12.57 & 11.72 & 0.284 & 23.77 & 12.33 & 0.054 \\
\hline Manufacturing & $22.01^{*}$ & 10.13 & 0.030 & $22.98^{*}$ & 10.15 & 0.024 & $32.45^{\star \star}$ & 10.68 & 0.002 \\
\hline Federal/ State Government & 11.52 & 10.33 & 0.265 & 11.88 & 10.33 & 0.250 & $21.75^{*}$ & 11.03 & 0.049 \\
\hline Adjacent to metro (Ref: Not Adjacent to metro) & & & & -7.56 & 5.36 & 0.158 & -5.95 & 5.38 & 0.269 \\
\hline \multicolumn{10}{|l|}{ \% Non-Hispanic Black (Ref: Q1) } \\
\hline Q2 & & & & & & & $-15.74^{*}$ & 6.70 & 0.019 \\
\hline Q3 & & & & & & & -4.51 & 8.00 & 0.573 \\
\hline Q4 & & & & & & & 0.10 & 11.50 & 0.993 \\
\hline \multicolumn{10}{|l|}{ \% Hispanic (Ref: Q1) } \\
\hline Q2 & & & & & & & -3.20 & 7.00 & 0.648 \\
\hline Q3 & & & & & & & 2.21 & 8.04 & 0.783 \\
\hline Q4 & & & & & & & 4.68 & 10.54 & 0.657 \\
\hline$\%$ residents age $65+$ & & & & & & & $9.33^{* *}$ & 3.08 & 0.002 \\
\hline \multicolumn{10}{|l|}{$\%$ residents age $25+$ with bachelor degree+ } \\
\hline \multicolumn{10}{|l|}{ Median household income } \\
\hline \multicolumn{10}{|l|}{$\%$ No health insurance } \\
\hline \multicolumn{10}{|l|}{ Health professional shortage area (Ref: no) } \\
\hline \multicolumn{10}{|l|}{ Physicians per 100,000 population (Ref: Q1) } \\
\hline \multicolumn{10}{|l|}{ Q2 } \\
\hline Q3 & & & & & & & & & \\
\hline
\end{tabular}




\begin{tabular}{lllllllll}
\hline Q4 \\
\% Trump vote, 2020
\end{tabular}

Table 4 cont: Stepwise Ordinary Least Squares Regression Models Predicting COVID-19 Mortality Rates for Rural Counties

\begin{tabular}{|c|c|c|c|c|c|c|c|c|c|}
\hline & \multicolumn{3}{|c|}{ Socioeconomic Predictors } & \multicolumn{3}{|c|}{ Health Care Predictors } & \multicolumn{3}{|c|}{ Trump Vote Share } \\
\hline & $\mathrm{b}$ & SE & $p$ & $\mathrm{~b}$ & SE & $p$ & $\mathrm{~b}$ & SE & $p$ \\
\hline \multicolumn{10}{|l|}{ Economic Dependence (Ref: Recreation) } \\
\hline Non-specialized & 17.93 & 9.69 & 0.064 & 18.68 & 9.86 & 0.058 & 18.77 & 9.91 & 0.058 \\
\hline Farming & 17.53 & 10.60 & 0.098 & $24.18^{*}$ & 10.80 & 0.025 & $24.35^{*}$ & 10.96 & 0.026 \\
\hline Mining & -3.46 & 12.50 & 0.782 & -1.16 & 12.62 & 0.927 & -1.04 & 12.69 & 0.935 \\
\hline Manufacturing & 8.21 & 10.78 & 0.447 & 10.25 & 10.94 & 0.349 & 10.35 & 11.00 & 0.347 \\
\hline Federal/ State Government & -2.49 & 10.97 & 0.820 & 0.92 & 11.15 & 0.934 & 0.97 & 11.16 & 0.930 \\
\hline Adjacent to metro (Ref: Not Adjacent to metro) & -3.46 & 5.26 & 0.511 & -1.99 & 5.30 & 0.707 & -2.06 & 5.36 & 0.700 \\
\hline \multicolumn{10}{|l|}{ \% Non-Hispanic Black (Ref: Q1) } \\
\hline Q2 & -11.15 & 6.53 & 0.088 & -11.18 & 6.55 & 0.088 & -11.16 & 6.56 & 0.089 \\
\hline Q3 & -4.74 & 7.79 & 0.543 & -4.67 & 7.84 & 0.552 & -4.67 & 7.84 & 0.552 \\
\hline Q4 & -7.26 & 11.21 & 0.517 & -4.71 & 11.31 & 0.677 & -4.98 & 11.68 & 0.670 \\
\hline \multicolumn{10}{|l|}{ \% Hispanic (Ref: Q1) } \\
\hline Q2 & 2.53 & 6.83 & 0.710 & 1.43 & 6.82 & 0.834 & 1.43 & 6.82 & 0.834 \\
\hline Q3 & 12.28 & 7.88 & 0.119 & 10.81 & 7.88 & 0.171 & 10.82 & 7.89 & 0.170 \\
\hline Q4 & 8.97 & 10.29 & 0.383 & 6.78 & 10.30 & 0.511 & 6.74 & 10.31 & 0.513 \\
\hline$\%$ residents age $65+$ & 4.26 & 3.05 & 0.163 & 5.83 & 3.24 & 0.072 & 5.89 & 3.31 & 0.075 \\
\hline$\%$ residents age $25+$ with bachelor degree+ & $-23.28^{\star \star \star}$ & 4.59 & $<0.001$ & $-27.07^{\star \star \star}$ & 4.86 & $<0.001$ & $-27.25^{\star * *}$ & 5.24 & $<0.001$ \\
\hline Median household income & $-29.24^{\star \star *}$ & 4.99 & $<0.001$ & $-27.27^{\star * \star}$ & 5.13 & $<0.001$ & $-27.12^{\star \star *}$ & 5.40 & $<0.001$ \\
\hline
\end{tabular}




\begin{tabular}{|c|c|c|c|c|c|c|c|c|c|}
\hline$\%$ No health insurance & & & & 4.03 & 3.52 & 0.252 & 3.98 & 3.56 & 0.264 \\
\hline Health professional shortage area (Ref: no) & & & & -5.86 & 9.13 & 0.521 & -5.85 & 9.14 & 0.522 \\
\hline \multicolumn{10}{|l|}{ Physicians per 100,000 population (Ref: Q1) } \\
\hline Q2 & & & & $13.97^{*}$ & 6.40 & 0.029 & $13.96^{*}$ & 6.40 & 0.029 \\
\hline Q3 & & & & $23.04^{* * *}$ & 6.84 & 0.001 & $23.02^{* * *}$ & 6.84 & 0.001 \\
\hline Q4 & & & & $23.83^{* *}$ & 8.06 & 0.003 & $23.80^{\star *}$ & 8.07 & 0.003 \\
\hline$\%$ Trump vote, 2020 & & & & & & & -0.38 & 4.10 & 0.926 \\
\hline Constant & $311.60^{\star * *}$ & 21.65 & $<0.001$ & $298.22^{\star \star \star}$ & 23.92 & $<0.001$ & $298.39^{\star \star \star}$ & 24.00 & $<0.001$ \\
\hline $\mathrm{R}^{2}$ & 0.461 & & & 0.465 & & & 0.465 & & \\
\hline
\end{tabular}

Notes: $\mathrm{N}=1,976$ rural counties. ${ }^{* *} \mathrm{p}<0.001,{ }^{* *} \mathrm{p}<0.01,{ }^{*} \mathrm{p}<0.05 . \mathrm{Q}=$ quartile. Mortality rates are current as of October 1,2021 . All models control for state fixed effects. 
Table 5: Stepwise Ordinary Least Squares Regression Models Predicting COVID-19 Infection Rates for Rural Counties

\begin{tabular}{|c|c|c|c|c|c|c|c|c|c|}
\hline & \multicolumn{3}{|c|}{ Economic Dependence } & \multicolumn{3}{|c|}{ Metro Adjacency } & \multicolumn{3}{|c|}{ Demographic Predictors } \\
\hline & b & SE & $p$ & b & SE & $p$ & b & SE & $p$ \\
\hline \multicolumn{10}{|l|}{$\begin{array}{l}\text { Economic Dependence (Ref: } \\
\text { Recreation) }\end{array}$} \\
\hline Non-specialized & $1,552.26^{\star \star \star}$ & 273.80 & $<0.001$ & $1,551.63^{\star \star \star}$ & 274.27 & $<0.001$ & $618.41^{*}$ & 276.21 & 0.025 \\
\hline Farming & 367.96 & 308.38 & 0.233 & 368.28 & 308.55 & 0.233 & -144.34 & 301.19 & 0.632 \\
\hline Mining & $1,211.26^{\star \star \star}$ & 352.25 & 0.001 & $1,211.65^{\star \star \star}$ & 352.46 & 0.001 & -81.08 & 356.21 & 0.820 \\
\hline Manufacturing & $2,155.58^{\star \star *}$ & 304.42 & $<0.001$ & $2,154.70^{\star \star \star}$ & 305.19 & $<0.001$ & $960.30^{* *}$ & 308.46 & 0.002 \\
\hline \multirow{2}{*}{$\begin{array}{l}\text { Federal/ State Government } \\
\text { Adjacent to metro (Ref: Not Adjacent } \\
\text { to metro) }\end{array}$} & $1,611.52^{\star * *}$ & 310.56 & $<0.001$ & $1,611.19^{\star \star \star}$ & 310.73 & $<0.001$ & 469.49 & 318.63 & 0.141 \\
\hline & & & & 6.90 & 161.13 & 0.966 & -160.36 & 155.41 & 0.302 \\
\hline \multicolumn{10}{|l|}{ \% Non-Hispanic Black (Ref: Q1) } \\
\hline Q2 & & & & & & & 209.32 & 193.50 & 0.280 \\
\hline Q3 & & & & & & & $527.15^{*}$ & 231.16 & 0.023 \\
\hline Q4 & & & & & & & -540.75 & 332.25 & 0.104 \\
\hline \multicolumn{10}{|l|}{ \% Hispanic (Ref: Q1) } \\
\hline Q2 & & & & & & & 161.72 & 202.10 & 0.424 \\
\hline Q3 & & & & & & & -8.68 & 232.24 & 0.970 \\
\hline Q4 & & & & & & & $645.45^{\star}$ & 304.27 & 0.034 \\
\hline $\begin{array}{l}\% \text { residents age } 65+ \\
\% \text { residents age } 25+\text { with bachelor } \\
\text { degree+ }\end{array}$ & & & & & & & $-989.59^{* * *}$ & 88.83 & $<0.001$ \\
\hline \multicolumn{10}{|l|}{ Median household income } \\
\hline $\begin{array}{l}\% \text { No health insurance } \\
\text { Health professional shortage area } \\
\text { (Ref: no) }\end{array}$ & & & & & & & & & \\
\hline
\end{tabular}




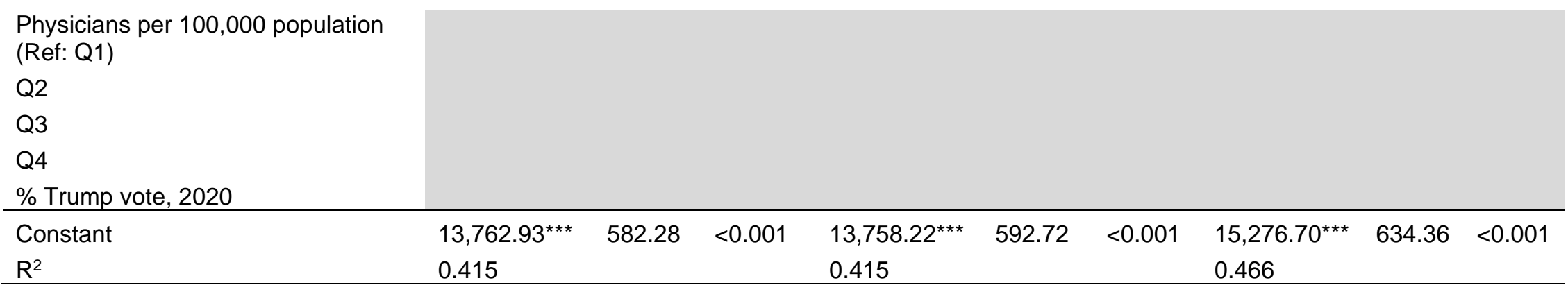

Table 5 cont: Stepwise Ordinary Least Squares Regression Models Predicting COVID-19 Infection Rates for Rural Counties

\begin{tabular}{|c|c|c|c|c|c|c|c|c|c|}
\hline & \multicolumn{3}{|c|}{ Socioeconomic Predictors } & \multicolumn{3}{|c|}{ Health Care Predictors } & \multicolumn{3}{|c|}{ Trump Vote Share } \\
\hline & $b$ & SE & $p$ & b & SE & $p$ & $\mathrm{~b}$ & SE & $p$ \\
\hline \multicolumn{10}{|l|}{$\begin{array}{l}\text { Economic Dependence (Ref: } \\
\text { Recreation) }\end{array}$} \\
\hline Non-specialized & 91.95 & 284.65 & 0.747 & -141.75 & 288.74 & 0.624 & -180.94 & 290.25 & 0.533 \\
\hline Farming & $-742.84^{*}$ & 311.48 & 0.017 & $-816.34^{\star *}$ & 316.46 & 0.010 & $-886.44^{* *}$ & 320.96 & 0.006 \\
\hline Mining & $-736.73^{*}$ & 367.19 & 0.045 & $-946.96^{\star}$ & 369.59 & 0.010 & $-996.62^{* *}$ & 371.49 & 0.007 \\
\hline Manufacturing & 405.49 & 316.88 & 0.201 & 209.57 & 320.46 & 0.513 & 168.31 & 321.97 & 0.601 \\
\hline $\begin{array}{l}\text { Federal/ State Government } \\
\text { Adjacent to metro (Ref: Not Adjacent }\end{array}$ & 74.48 & 322.25 & 0.817 & -140.07 & 326.46 & 0.668 & -161.35 & 326.81 & 0.622 \\
\hline \multicolumn{10}{|l|}{ \% Non-Hispanic Black (Ref: Q1) } \\
\hline Q2 & 307.98 & 191.99 & 0.109 & 227.14 & 191.89 & 0.237 & 220.24 & 191.93 & 0.251 \\
\hline Q3 & $542.89^{*}$ & 228.76 & 0.018 & 392.37 & 229.68 & 0.088 & 393.28 & 229.64 & 0.087 \\
\hline Q4 & $-646.17^{\star}$ & 329.34 & 0.050 & $-820.81^{*}$ & 331.17 & 0.013 & $-709.48^{*}$ & 341.99 & 0.038 \\
\hline \multicolumn{10}{|l|}{ \% Hispanic (Ref: Q1) } \\
\hline Q2 & 261.23 & 200.55 & 0.193 & 256.50 & 199.68 & 0.199 & 256.70 & 199.65 & 0.199 \\
\hline
\end{tabular}




\begin{tabular}{|c|c|c|c|c|c|c|c|c|c|}
\hline Q3 & 157.07 & 231.41 & 0.497 & 209.21 & 230.92 & 0.365 & 202.10 & 230.94 & 0.382 \\
\hline Q4 & $643.18^{*}$ & 302.26 & 0.033 & $701.74^{*}$ & 301.65 & 0.020 & $716.44^{*}$ & 301.80 & 0.018 \\
\hline $\begin{array}{l}\% \text { residents age } 65+ \\
\% \text { residents age } 25+\text { with bachelor }\end{array}$ & $-1,039.09^{\star * *}$ & 89.75 & $<0.001$ & $-1,160.28^{\star \star \star}$ & 94.80 & $<0.001$ & $-1,186.52^{* * *}$ & 96.91 & $<0.001$ \\
\hline degree+ & $-730.05^{\star * *}$ & 134.82 & $<0.001$ & $-930.69^{\star \star \star}$ & 142.43 & $<0.001$ & $-856.53^{\star \star *}$ & 153.39 & $<0.001$ \\
\hline Median household income & -126.39 & 146.49 & 0.388 & -238.37 & 150.15 & 0.113 & -303.28 & 158.20 & 0.055 \\
\hline $\begin{array}{l}\% \text { No health insurance } \\
\text { Health professional shortage area } \\
\text { (Ref: no) } \\
\text { Physicians per } 100,000 \text { population } \\
\text { (Ref: Q1) }\end{array}$ & & & & $\begin{array}{l}-421.93^{\star \star *} \\
95.85\end{array}$ & $\begin{array}{l}103.09 \\
267.49\end{array}$ & $\begin{array}{l}<0.001 \\
0.720\end{array}$ & $\begin{array}{l}-401.42^{\star \star \star} \\
89.48\end{array}$ & $\begin{array}{l}104.27 \\
267.49\end{array}$ & $\begin{array}{l}<0.001 \\
0.738\end{array}$ \\
\hline Q2 & & & & 358.72 & 187.49 & 0.056 & 362.78 & 187.48 & 0.053 \\
\hline Q3 & & & & $533.63^{\star *}$ & 200.27 & 0.008 & $539.19^{\star *}$ & 200.28 & 0.007 \\
\hline Q4 & & & & $569.64^{*}$ & 236.13 & 0.016 & $580.54^{*}$ & 236.23 & 0.014 \\
\hline$\%$ Trump vote, 2020 & & & & & & & 155.98 & 119.91 & 0.193 \\
\hline Constant & $15,167 \cdot 38^{\star \star \star}$ & 636.17 & $<0.001$ & $14,928.98^{\star \star \star}$ & 700.66 & $<0.001$ & $14,856.20^{* * *}$ & 702.76 & $<0.001$ \\
\hline $\mathrm{R}^{2}$ & 0.478 & & & 0.485 & & & 0.486 & & \\
\hline
\end{tabular}

